\title{
Daniel Rodrigues Stuginski
}

“Termofilia e Termogênese pós-prandiais em Bothrops moojeni (Serpentes:Viperidae) em cativeiro”

São Paulo

2009 


\section{Daniel Rodrigues Stuginski}

\section{“Termofilia e Termogênese pós-prandiais em Bothrops moojeni (Serpentes:Viperidae) em cativeiro”}

Dissertação apresentada ao Instituto de Biociências da Universidade de São Paulo, para a obtenção de Título de Mestre em Ciências, na Área de Fisiologia.

Orientador: Augusto Shinya Abe

São Paulo 


\section{Ficha Catalográfica}

\section{Stuginski, Daniel Rodrigues}

“Termofilia e termogênese pós-prandiais em ops moojeni (Serpentes:Viperidae) em Cativeiro”

\section{5 páginas}

Dissertação (Mestrado) - Instituto de Biociências da Universidade de São Paulo. Departamento de Fisiologia.

1. Termofilia

2. Termorregulação

3.Bothrops moojeni

I. Universidade de São Paulo. Instituto de Biociências. Departamento de Fisiologia.

\section{Comissão Julgadora:}

Prof(a). Dr(a).

Prof(a). Dr(a).
$\operatorname{Prof(a).~Dr(a).~}$

Prof(a). Dr(a).

Prof(a). Dr.(a).

Orientador(a) 


\section{Dedicatória}

Dentre tantas pessoas sem as quais eu jamais teria terminado este trabalho...escolhi dedicá-lo a duas sem as quais seria impossível ter sequer começado...a minha mãe e entusiasta Maria Isabel Rodrigues e a meu amigo e "chefe" Wilson Fernandes. 


\section{Epígrafe}

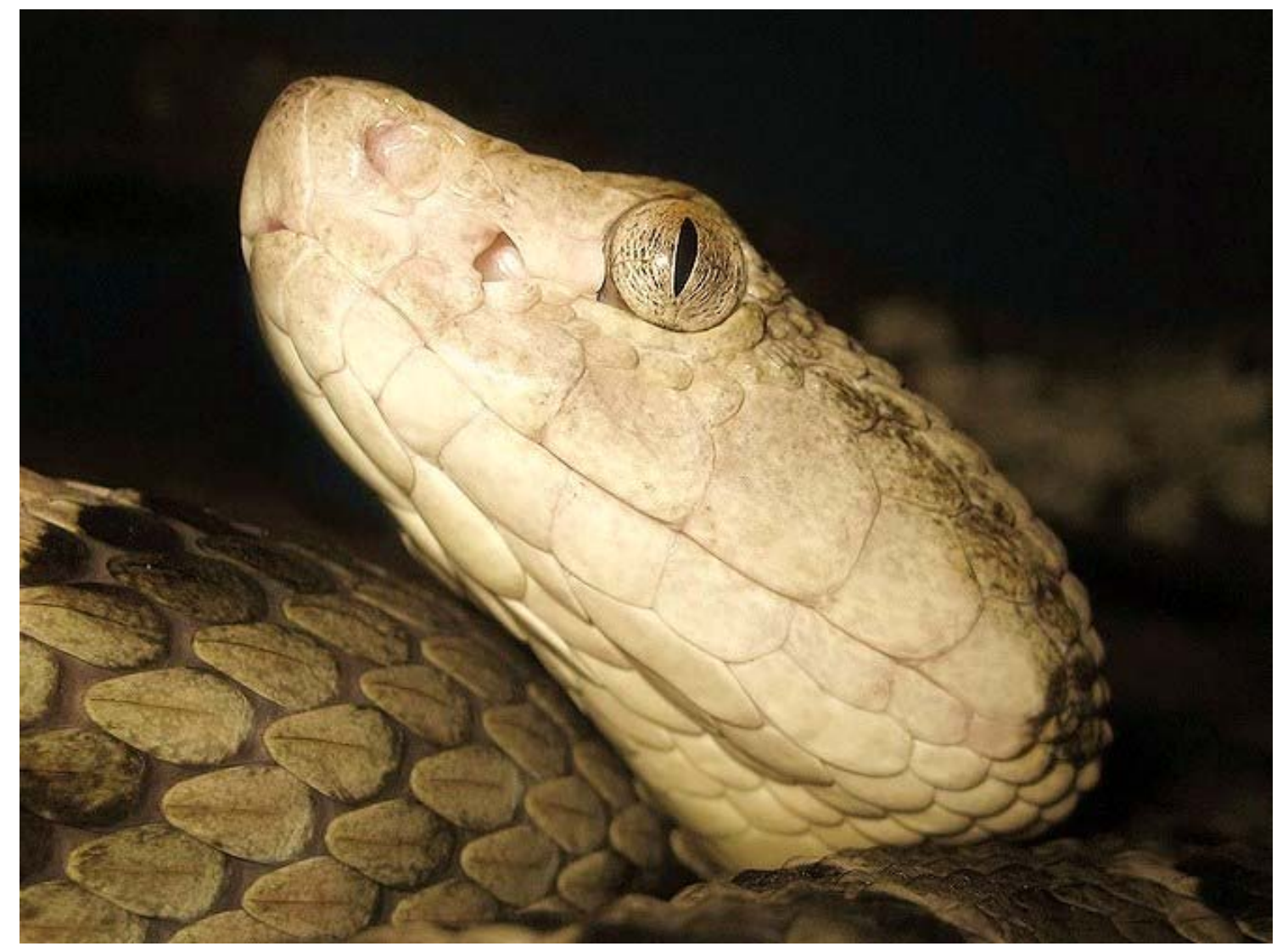

“As convicções são inimigas mais perigosas da verdade do que as mentiras”.

Friedrich Nietzsche 


\section{Agradecimentos}

Agradeço:

Ao meu orientador Augusto Shinya Abe por ter me orientado e me dado o suporte necessário durante esta etapa.

Ao meu chefe e amigo Wilson Fernandes por ter sempre acreditado em mim e me apoiado irrestritamente ao longo destes anos.

A Kathleen Grego Fernandes e Sávio Stefanini Sant’Anna por todo o companheirismo carinho e dedicação que estão presentes em cada vírgula deste trabalho.

Ao meu colaborador Gleen Tattersall, por ter feito comigo toda a parte experimental da termogênese pós-prandial.

Ao Prof. José Guilherme Berlinck Chauí, por ter me salvado do inferno estatístico e ter melhorado muito a qualidade deste trabalho.

Ao Professor Gilberto, por toda ajuda de trâmites burocráticos ao longo destes anos.

Aos professores Carlos Navas, José Bicudo e José Carvalho por terem participado da minha banca de qualificação.

A FAPESP, pelo apoio financeiro sem o qual não poderia ficar.

Aos meus amigos e ex Fundaps ( Marília, Alexandre, Nicoleti, Philipp, Paula, Jeanine e Hess) por toda ajuda e risadas ao longo desses anos.

A Dra Maria de Fátima Furtado pelos trabalhos e discussões produtivas ao longo desses anos.

Ao meu amigo Antonio de Pádua Bordingnon Fernandes pela amizade e por ter me ajudado muito em todos os aspectos do trabalho, principalmente, com as fotos deste manuscrito. Aos meus amigos (Matheus Gallo, Rodrigó, Flecha, Alex e Lú) por toda a ajuda, direta ou indireta no trabalho.

A Fernanda Devidé Monteiro de Castro, pelo apoio.

Aos médicos e corpo de enfermagem do Hospital Vital Brazil que não deixaram minha mão necrosar e cair quando fui acidentado. 
Aos meus professores de pós-graduação que tentaram a duras penas fazer com que eu me torna-se uma pessoa mais instruída nesses anos.

Aos meus “amigos de pós” que compartilharam comigo de todas as angústias e desventuras que só a pós-graduação faz por você.

Aos meus amigos “Bossais”, por tornarem minha vida sempre mais leve e animada.

Aos meus colegas de laboratório (Sílvia, Marisa, Thélia, Eliana, Marcelo, Dona Vera, Dona

Lúcia, Toninho, Carlão, Valério, Chicão e Solange) pelo apoio intelectual e logístico.

A minha mãe (Maria Isabel Rodrigues) pelo amor, confiança e paciência que sempre me dedicou.

A meu pai (Luis Antônio Stuginski) por ter me dado as condições necessárias para que pudesse correr atrás do meu sonho.

A meus irmãos (Tatiana e Cristiano) por terem suportado tão bem essa minha paixão pelas serpentes ao longo de uma vida.

A Ana Helena Pagotto (minha namorada linda!), por toda a ajuda, dedicação e apoio nos momentos conturbados, por me fazer muito feliz.

A meus famíliares de maneira geral que acompanharam esta luta desde que ela começou, não há 2 anos e pouco e sim a 28 anos atrás.

e a Deus...não por ter conseguido terminar este projeto...mas por ter todos vocês supracitados na minha vida. 


\section{Índice:}

Capítulo 1: Introdução Geral

Capítulo 2: Material e Métodos

Capítulo 3: Temperatura Preferencial e Termofilia pós-prandial em Bothrops moojeni (Serpentes: Viperidae).

Capítulo 4: Ritmo circadiano em Bothrops moojeni em cativeiro (Serpentes: Viperidae).

Capítulo 5: Termogênese pós-prandial em Bothrops moojeni (Serpentes: Viperidae). Capítulo 6: Considerações Finais. 


\section{Capítulo 1: Introdução Geral}

1.1) Termorregulação nas serpentes: As serpentes são representadas por mais de 2700 espécies, divididas em 18 famílias, que estão distribuídas por todo o globo à exceção dos pólos (Greene, 1997). As serpentes, tais quais os demais répteis, são ectotérmicas, ou seja, são animais incapazes de gerar grande quantidade de calor através de seu metabolismo e sustentar esta temperatura corpórea por longos períodos, o que influencia muito seu estilo de vida (Cowles \& Bogert, 1944; Pough, 1980).

A grande maioria das atividades das serpentes, desde a percepção dos órgãos dos sentidos, capacidade de locomoção, produção espermática, digestão, entre outras, estão em algum nível, ligadas à temperatura (Lysenko \& Gillis, 1980; Naulleau, 1983; Stevenson et al, 1985; Sievert, 2005). Entretanto, diferentes atividades possuem diferentes temperaturas ótimas, assim sendo muitos destes animais estão sempre dinamicamente adequando suas temperaturas corporais conforme suas necessidades fisiológicas.

A importância da termorregulação na vida das serpentes varia enormemente conforme suas relações filogenéticas, sua distribuição geográfica, seu status fisiológico entre outros fatores, já que tanto as necessidades quanto as oportunidades termorregulatórias são bastante diversas no grupo (Heath, 1964; Huey, 1982; Shine \& Lambeck, 1985; Slip \& Shine, 1988).

As serpentes noturnas são modelos especialmente interessantes nos estudos de termorregulação, pois durante seu período de atividade geralmente possuem pouca 
possibilidade termorregulatória (Hertz et al, 1993; Roe et al 2004), o que pode representar um grande desafio na sustentação de processos fisiológicos primordiais, como por exemplo, a digestão. Aliado a este fato, o hábito de ingerir presas de grande tamanho (como é o caso de muitos crotalinae) pode tornar ainda mais complexa a manutenção da homeostase.

Nos próximos capítulos discutiremos através de experimentos empregados numa serpente crotalinae em cativeiro, como alguns fatores ligados aos hábitos destes animais como: a atividade noturna, a pouca mobilidade e a ingestão de grandes presas podem afetar seus regimes térmicos e qual é a implicação destas diretrizes na vida dos animais.

1.2) Bothrops moojeni: A serpente Bothrops moojeni (Hoge, 1966), popularmente conhecida como caiçaca (Fig. 1.1), pertence à família dos Viperídeos e possui ampla distribuição na América do Sul, sendo especialmente abundante no Brasil, (Lellop, 1984). Habita as áreas de cerrado e está geralmente relacionada às matas de galeria e, ocasionalmente, a áreas secas de savanas interfluviais (Lellop, 1984; Campbell \& Lamar, 2004; Borges \& Araújo, 1998; Martins et al, 2002; Nogueira et al, 2003). Pode alcançar $230 \mathrm{~cm}$ de comprimento, sendo que em sua maioria não atingem mais de $160 \mathrm{~cm}$ (Campbell \& Lamar, 2004). Apresentam dimorfismo sexual no tamanho, sendo as fêmeas maiores do que os machos (Nogueira et al, 2003). A caiçaca apresenta dieta generalista e bastante variada, consistindo de anfíbios, lagartos e roedores, sendo que existe uma mudança ontogenética em sua dieta (Andrade et al, 1996; Nogueira et al, 2003). Assim, quando filhotes, tendem a comer presas ectotérmicas e quando adultos, a maioria dos itens consumidos são endotérmicos. São serpentes de hábitos noturnos (Nogueira et al, 2003) tal 
qual a maiorias das outras Bothrops sendo que, na maior parte do tempo, adotam a tática "sit and wait" de caça, típica dos viperídeos, permanecendo enrodilhadas em espreita aguardando a passagem de uma eventual presa.

A escolha de Bothrops moojeni como modelo experimental deveu-se ao fato da espécie apresentar uma série de características ecológicas interessantes para os estudos termobiológicos, como: o hábito noturno, a pouca mobilidade e a capacidade de alimentarse de presas proporcionalmente grandes. Aliadas a estas características, a grande representatividade do gênero na América Latina e a ampla distribuição geográfica da espécie no território nacional (Fig 1.2), endossaram a nossa escolha. (Lellop, 1984; Campbell \& Lamar, 2004; Nogueira et al 2003).

Figura 1.1: Exemplar de Bothrops moojeni, fêmea, $110 \mathrm{~cm}$, procedente de Pirassununga-SP.

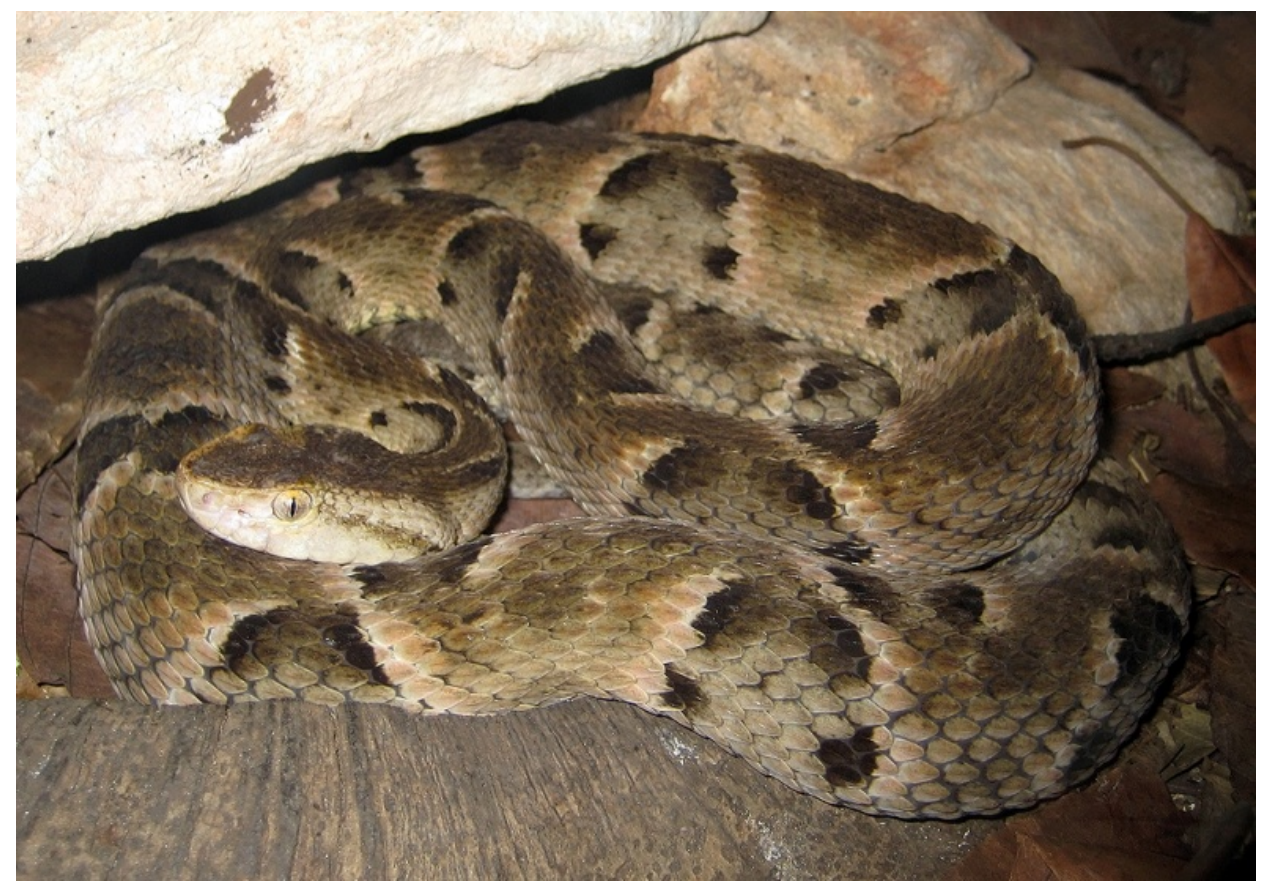


Figura. 1.2: Distribuição geográfica de Bothrops moojeni.

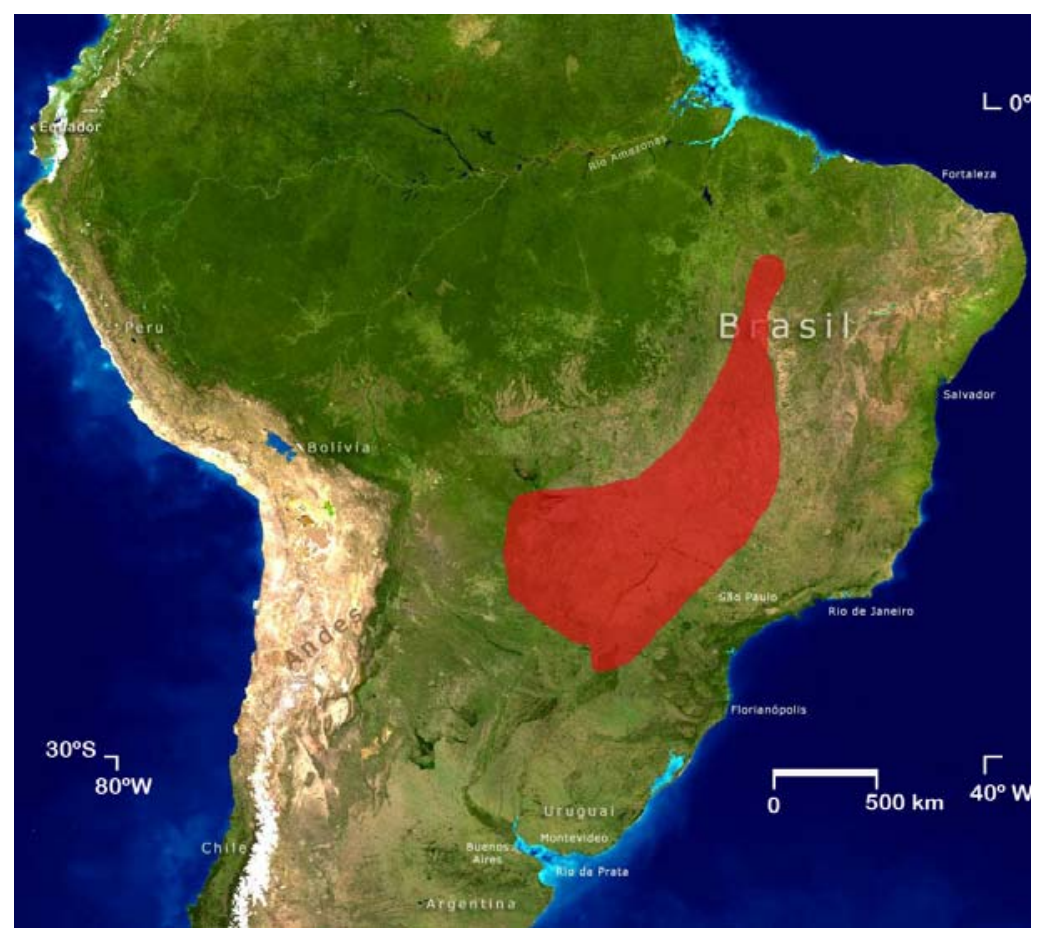

\section{Referências bibliográficas:}

Andrade, D.V.; Abe, A. S.; Santos M. C. (1996). Is the venom related to diet and tail color during Bothrops moojeni ontogeny? J. Herpetol., 30: 285-288.

Borges, R. C. \& Araújo, A. F. B. (1998). Seleção de habitat em duas diferentes espécies de jararaca (Bothrops moojeni, Hoge and Bothrops neuwiedi, Wagler) (Serpentes: Viperidae). Revista Brasileira de Biologia, 58: 591-601.

Campbell, J. A. \& Lamar, W. W. (2004). Venomous of the western hemisphere, vol. 1, Cornell Univers, Press, Ithaca, New York 
Cowles, R. B. \& Bogert, C. M. (1944). A preliminary study of thermal requirements of desert reptiles. Bull. Am. Mus. Nat. Hist. 83, 261-296.

Greene, H. W. (1997). In Snakes: The Evolution of Mystery in Nature, Univers. California. Press. London.

Heath, J. E. (1964). Reptilian thermorregulation: evaluation of field studies. Science 146, 784-785.

Hertz, P. E.; Huey, R. B.; Stevenson, R. D. (1993). Evaluating Temperature Regulation by Field-Active Ectotherms: The Fallacy of the Inappropriate Question The American Naturalist, Vol. 142, No. 5. (Nov., 1993), pp. 796-818

Huey, R. B. (1982). Temperature physiology and ecology of reptiles. In Biology of Reptilia. (Edited by Gans C. and Pough F. H.), vol. 12, pp 25-91. Academic press, London. Lellop, P. (1984). Various aspects of venomous snake breeding on a large scale, Acta Zool., Pathol., Antverp, 78:177-198,

Lysenko, S. \& Gillis, J. E. (1980). The effect of ingestive status on thermorregulatory behavior of Thamnophis sirtalis sirtalis and Thamnophis sirtalis parietalis. J. Herpetol. 14, 155-159.

Martins, M.; Marques, O. A V.; Sazima, I. (2002). Ecological and phylogenetic correlates of feeding habits in Neotropical pitvipers (genus Bothrops). In Schuett G. W.; Hoggren M.; Douglas M. E. And Greene H. W. In Biology of the Vipers, pp 307-328, Eagle Mountain Publishing, Eagle Mountain, UT.

Naulleau, G. (1983). The effects of temperature on digestion in Vipera aspis. J. Herpetol. 16, 166-177. 
Nogueira, C.; Sawaya, R. J.; Martins, M. (2003). Ecology of the pitviper, Bothrops moojeni, in the Brazilian cerrado. J. Herpetol., vol. 37, n4, pp 653-659.

Pough, F. H. (1980). The advantages of ectothermy for tetrapods. Am. Nat. 115, 92-112.

Roe, J. H.; Hopkins, W. A.; Snodgrass, J. W.; Congdon, J. D. (2004). The influence of circadian rhythms on pre- and post-prandial metabolism in the snake Lamprophis fuliginosus. Comp. Bioch. Physiol., part A 139, pp 159-168.

Sievert, L. M.; Jones, D. M.; Puckett, M. W. (2005). Postprandial thermophily, transit rate and digestive efficiency of juvenile cornsnake, Pantherophis guttatus. J. Thermal biology, vol 30, pp 354-359.

Slip, D. J. \& Shine, R. (1988). Thermorregulation of free-ranging diamond pythons, Morellia spilota (Serpentes, Boidae). Comp.Biochem.Physiol. vol 89a, n 4, pp 645-650.

Shine, R. \& Lambeck, R. (1985). A radiothelemetric study of movements, thermorregulation and habitat utilization of Arafura filesnake (Serpentes: Acrochordidae), Herpetologica, 41: 351 .

Stevenson, R. D.; Peterson, C. R.; Tsuji, J. S. ( 1985). The thermal dependece of locomotion, tongue flicking, digestion and oxigen consuption in wandering garter snake. Physiol. Zool. 58, 46-57. 


\section{Capítulo 2: Material e Métodos:}

Foram utilizados nos experimentos 29 exemplares de Bothrops moojeni, nascidas em cativeiro, no Laboratório de Herpetologia do Instituto Butantan São Paulo, Brasil, em 2005. Os experimentos foram realizados durante o período de janeiro de 2007 a setembro de 2008. Os animais foram mantidos durante esse período no próprio biotério do Laboratório de Herpetologia do Instituto Butantan, numa sala cuja temperatura variou entre $20^{\circ} \mathrm{C}$ e $30^{\circ} \mathrm{C}$, fotoperíodo de $12 / 12$ horas (claro/escuro). As serpentes foram mantidas individualizadas dentro de caixas de madeira medindo $45 \times 35 \times 20 \mathrm{~cm}$, forradas com papelão corrugado. A água foi fornecida ad libitum e a alimentação oferecida a cada 30 dias. A alimentação dos animais foi constituída por camundongos (Mus musculus) provenientes do Biotério Central do Instituto Butantan. Durante todo o período experimental as serpentes foram monitoradas quanto à alimentação, trocas de pele e crescimento, não tendo apresentado nenhum problema de saúde neste período. Durante o período experimental as serpentes foram manipuladas o mínimo possível e sempre através de gancho herpetológico. Quando a contenção foi necessária, foi utilizado o laço de Lutz. Os animais não foram submetidos à extração de veneno ou procedimentos de contenção química. 


\section{Capítulo 3: "Temperatura preferencial e termofilia pós-prandial em Bothrops moojeni em cativeiro (Serpentes: Viperidae)"}

$\underline{\text { Stuginski, D. R. }{ }^{1} ;}$ Abe, A. S. ${ }^{2}$; Fernandes, W. ${ }^{3}$

Departamento de Fisiologia do IB-USP ${ }^{1}$, Departamento de Zoologia da Unesp-Rc ${ }^{2}$, Laboratório de Herpetologia do Instituto Butantan ${ }^{3}$

\subsection{1) Abstract:}

The study of the preferred temperatures and thermophilic behavior is essential to understand the snake's thermal biology. Although some studies have been reported, most of them are focused in temperate and diurnal species. Thus, little is known about the tropical and sub-tropical nocturnal species. In the present study, a video-monitored arena with a thermal gradient was used to investigate the preferred thermal range during activity and inactivity (Tset) and the post-prandial thermophilic response after different levels of food intake in 29 Brazilian lanceheads (Bothrops moojeni). The results showed that the preferred thermal range of B.moojeni changes depending on the photoperiod $\left(20.93^{\circ} \mathrm{C}\right.$ to $22.20^{\circ} \mathrm{C}$ in daytime and $22.81^{\circ} \mathrm{C}$ to $24.42^{\circ} \mathrm{C}$ in night time), being similar to other crotalinae snakes. Our data suggests that there is an inverse correlation between the post-prandial thermophilic response intensity and food intake, as animals fed with a portion corresponding to $10 \%$ of its bodyweight presented a higher thermophilic response in comparison to those who were fed with larger portions (20 and $40 \%$ of bodyweight). This 
difference may be related to the decreased mobility and increased SDA (Specific Dynamic Action) in animals that consumed the largest amount of food.

Key words: Post-prandial, thermophilic behavior, SDA, digestion.

\subsection{2) Resumo:}

$\mathrm{O}$ estudo das temperaturas preferenciais e comportamento termofílico é essencial na compreensão da termobiologia das serpentes, todavia, a maioria dos trabalhos tem focado somente os animais diurnos e de clima temperado e pouco se sabe a respeito das serpentes noturnas tropicais e sub-tropicais. O presente estudo utilizou uma arena com gradiente térmico monitorada por vídeo para mensurar o intervalo térmico preferencial procurado durante os períodos de atividade e inatividade (Tset) e a resposta termofílica pós-prandial frente a diferentes quantidades de ingesta em 29 serpentes Bothrops moojeni . Os resultados obtidos mostraram que o intervalo térmico preferencial de B.moojeni diferiu conforme o fotoperíodo $\left(20,93^{\circ} \mathrm{C}\right.$ a $22,20^{\circ} \mathrm{C}$ durante o dia e $22,81^{\circ} \mathrm{C}$ a $24,42^{\circ} \mathrm{C}$ durante a noite) e foi similar a outros intervalos encontrados para outras serpentes crotalinae. Os dados mostraram que há uma correlação inversa entre intensidade da resposta termofílica pósprandial e quantidade de alimento ingerido, uma vez que os animais alimentados com uma porção correspondente a $10 \%$ de seu peso corporal apresentaram maior resposta termofílica pós-prandial quando comparados àqueles que foram alimentados com porções maiores (20 e $40 \%$ do peso corporal). Esta diferença parece estar relacionada com a diminuição de mobilidade e a maior SDA (Specific Dynamic Action) nos animais que ingeriram a maior quantidade de alimento. 


\section{2) Introdução:}

O paradigma da termorregulação como a pedra fundamental na vida dos répteis, preconizada por Cowles \& Borget (1944) e Bogert (1949, 1959), tem sido questionado e reavaliado ao longo dos anos (Heath, 1964, 1970; Avery, 1982; Angilletta et al, 2002;). A inserção de variáveis como o custo termorregulatório, bem como a repetida detecção da termoconformidade entre as diferentes espécies, aumentou muito o leque de possibilidades termais dentre os répteis (McGinis, 1970; Hertz, 1974, 1992; Stevenson 1985a, 1985b). Anteriormente acreditava-se que os répteis tentassem manter sua temperatura corporal próxima a uma temperatura ótima fixa (Brattstrom, 1965). Hoje sabemos que as diversas atividades desempenhadas por estes animais têm diferentes temperaturas ótimas (Avery, 1982). Com isto, uma visão mais lábil da temperatura ótima foi estabelecida, na qual, estes animais tentariam manter-se dentro de um intervalo de temperatura ótima durante seu período de atividade (Barber \& Crawford, 1977; Bartholomew, 1982; Huey, 1982; Huey \& Hertz, 1984). Esta faixa térmica ótima é influenciada por fatores intrínsecos e extrínsecos, como a sazonalidade, distribuição geográfica, variação ontogenética, sexo, além dos diferentes estados fisiológicos (Withers \& Campbell, 1985; Van Damme et al, 1986; Gibson et al, 1989; Gvozdik, 2002). A precisão da termorregulação nos répteis pode ser avaliada mediante a três fatores: As temperaturas que os animais buscam na natureza, as temperaturas disponíveis para estes animais nos diferentes habitats e a faixa térmica preferencial que estes animais buscam em cativeiro com plenas possibilidades termorregulatórias (Hertz et al, 1993).

O intervalo térmico preferencial (Tset) é determinado através da mensuração da faixa térmica que os animais procuram sob total possibilidade termorregulatória em arenas 
térmicas. A Tset representa o intervalo térmico de ótimo desempenho fisiológico, ou seja, o intervalo térmico no qual as diferentes atividades fisiológicas estão maximizadas. As temperaturas ótimas fisiológicas (Tset) e ecológicas (mensuradas através das temperaturas corporais em natureza) podem diferir significativamente, já que nem sempre é possível para os animais em natureza manter suas temperaturas próximas ao ótimo fisiológico (Licht et al 1966; Licht, 1967; Huey et al, 1977; Huey, 1982; Withers \& Campbell, 1985; Hutchinson \& Dupré, 1992; Hertz et al, 1993; Lailvaux et al, 2003). A quantidade de dados a respeito de temperaturas corporais dos répteis em campo é bastante grande (Huey et al, 1977), porém poucos dados a respeito das Tset's foram amostrados, apesar da importância da associação de ambos os parâmetros para estabelecer a acuidade termorregulatória dos animais (Hertz et al, 1993).

As serpentes possuem uma particularidade anatômica que influencia muito suas trocas térmicas: são cilíndricas e possuem uma grande superfície corpórea em relação ao seu volume. Devido a este fato, quando expostas a alguma fonte de calor, aumentam de temperatura rapidamente, porém, com igual facilidade resfriam, caso não recorram a ajustes fisiológicos e comportamentais (Lillywhite, 1987). A importância da termorregulação nas atividades das serpentes varia bastante conforme a espécie em questão (Shine \& Lambeck, 1985; Shine, 1987; Sievert et al; 2005). Em geral as serpentes não são tidas como termorreguladoras "cautelosas", ou seja, costumam manter suas atividades dentro de faixas térmicas mais amplas do que outros répteis. (Avery, 1982). A termorregulação em serpentes, principalmente no caso de serpentes diurnas e residentes em faixas de clima temperado, já foi bem documentada, diferentemente do que ocorre no caso das serpentes 
noturnas (Carpenter, 1956; Gibson \& Falls, 1979; Naulleau, 1983 Lillywhite, 1987; Rosen, 1991; Brown \& Weatherhead, 2000).

Alguns trabalhos têm demonstrado que a termorregulação têm um papel reduzido na vida de animais que habitam locais de pouca variabilidade de térmica ou que possuem uma grande inércia térmica devido a sua massa (termoconformadores) (Shine \& Lambeck, 1985; Daltry et al, 1998; Shine et al , 2003). Ainda assim, comportamentos termofílicos podem ser observados nestes animais durante determinadas situações, como por exemplo, no período pós-prandial (Slip \& Shine, 1988b). Sabidamente algumas serpentes procuram manter a temperatura corpórea mais elevada, após a ingestão de presas, (Regal, 1966; McGinnis \& Moore, 1969; Greenwald \& Kanter, 1979; Lysenko \& Gillis, 1980; Huey, 1982; Naulleau, 1983; Lillywhite, 1987, Sievert \& Andreadis, 1999, Sievert et al, 2005). Esta resposta termofílica pós-prandial observada em alguns animais ocorre, aparentemente, na tentativa de acelerar o processo digestório e, ao menos em alguns casos, também parece aumentar o ganho energético (Toledo et al, 2003).

A temperatura ambiente, quantidade de alimento ingerido e a espécie em questão são fatores importantes na determinação da resposta termofílica pós-prandial (Andrade et al, 1997). Um processo digestório mais rápido e energeticamente rentável pode ser vantajoso em termos de "custo" a muitos ectotérmicos, porém nem todos os animais parecem contemplar a mesma regra (Huey \& Slatkin, 1976). A resposta termofílica pós-prandial, assim como outras manobras termorregulatórias da vida dos ectotermos, tem um custo a ela atrelado. Este custo pode estar relacionado à energia despendida na procura de locais próprios para a termorregulação, ou mesmo ao risco de predação durante o deslocamento dos animais. Por esse motivo a termofilia pós-prandial, assim como outros comportamentos 
termorregulatórios, parece ser mediada pela questão custo x benefício (Huey, 1974; Huey \& Slatkin, 1976; Hutchinson \& Dupré, 1992). A existência ou não de resposta termofílica pós-prandial nos animais noturnos e que habitam locais de poucas possibilidades termorregulatórias, pode ajudar a esclarecer a relação das necessidades ecológicas e fisiológicas destes animais.

As serpentes crotalinae do gênero Bothrops, figuram entre os animais capazes de ingerir presas de grandes proporções, além disso, são tidas como animais essencialmente noturnos que caçam principalmente por espreita (Campbell \& Lamar, 2004), e capazes de períodos razoavelmente longos de jejum. A ingestão de grandes presas por parte de serpentes noturnas e de pouca possibilidade termorregulatória, pode significar um grande desafio à digestão. O presente trabalho teve como objetivos determinar as temperaturas preferenciais (Tset) da serpente Bothrops moojeni em cativeiro em seus períodos de atividade e de inatividade, bem como avaliar e quantificar a eventual resposta termofílica pós-prandial, após a ingestão de presas de diferentes tamanhos.

\section{3) Material e métodos:}

\subsection{1) Manutenção dos animais: Ver em Materiais e Métodos Cap. 2}

3.3.2) Arena Térmica: Para os estudos de termofilia os animais foram colocados em um terrário de vidro com fundo de metal, de dimensões de 180 × 60 × $80 \mathrm{~cm}$, com substrato de terra previamente esterilizada em estufa mantida a $130^{\circ} \mathrm{C}$ por 6 horas. Um gradiente térmico foi estabelecido com o uso de um aquecedor simples de resistência (220v) em uma das extremidades e um resfriador Coel ${ }^{\circledR}(220 v)$ na outra. Com este dispositivo o gradiente 
de temperatura dentro do terrário foi de $36^{\circ} \mathrm{C}-17^{\circ} \mathrm{C}\left(+\right.$ ou $\left.-2^{\circ} \mathrm{C}\right)$, permitindo que os animais pudessem termorregular conforme suas necessidades.

Sobre o gradiente térmico foram demarcados 40 quadrantes de $15 \times 15 \mathrm{~cm}$, através do uso de barbantes colocados sobre a terra e presos nas laterais do terrário com fita adesiva, não atrapalhando deslocamento das serpentes. O terrário foi dividido ao meio em seu eixo principal através de uma placa de madeirite, formando duas arenas com 20 quadrantes de comprimento e dois quadrantes de largura (fig. 3.1), ambas com uma porção aquecida e a outra resfriada. Em uma das arenas algumas pequenas barreiras $(10,0 \times 6,0 \times 0,5 \mathrm{~cm})$ foram colocadas com a finalidade de detectar se a presença de anteparos poderia influir no deslocamento e na resposta termofílica dos animais, como já foi descrito anteriormente em Tsai \& Tu (2005).

Figure 3.1: Arenas térmicas

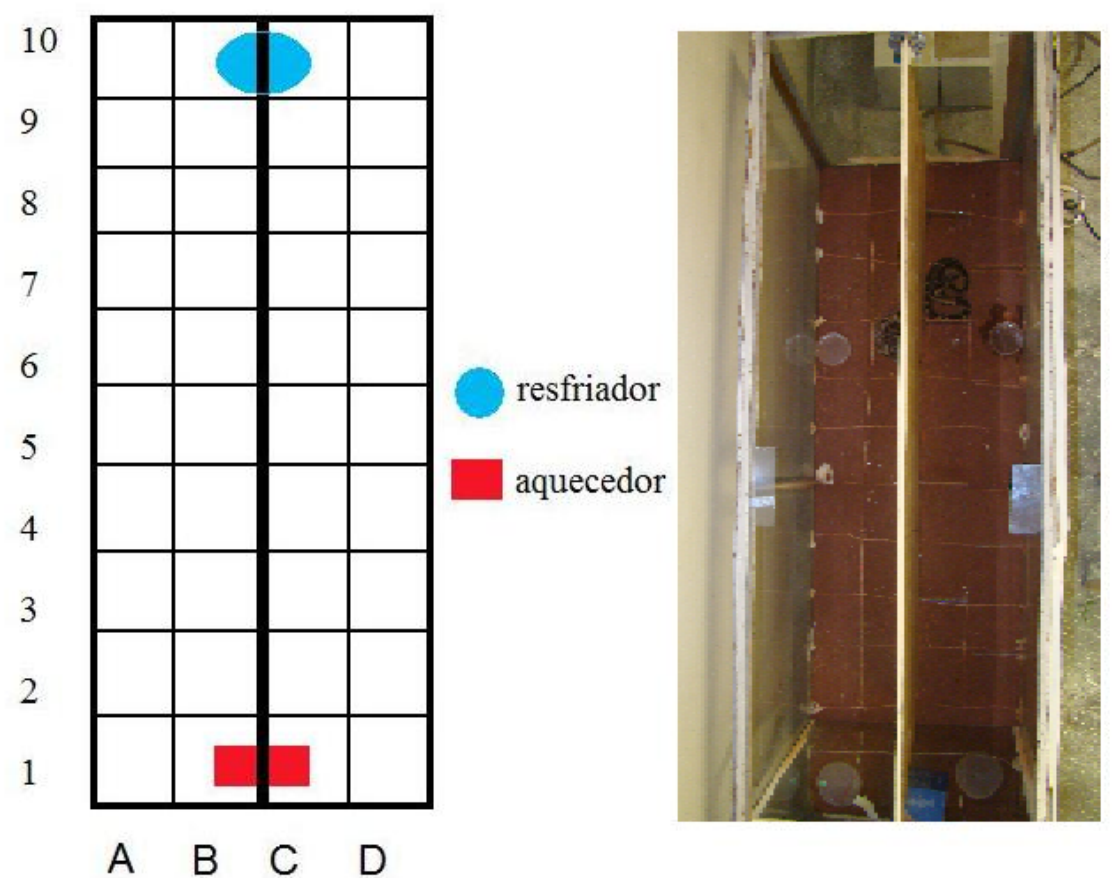


3.3.3) Grupos experimentais e monitoramento: Os 29 animais foram divididos em três grupos A, B e C que foram alimentados respectivamente com 40, 20 e 10\% de seu próprio peso em alimento. A cada sessão experimental foi colocada uma serpente em cada uma das arenas e ambas monitoradas através "web cam" ligada a um computador Pentium III. A captura das imagens noturnas foi feita com auxilio de led's infravermelhos próprios para filmagens no escuro. As imagens foram analisadas através de fotos tomadas automaticamente a cada 60 segundos pelo programa HSSVSS 6.06. Assim, a cada dia foram tomadas cerca de 1440 fotos, que capturaram a movimentação nas duas arenas. Todos os animais foram colocados na arena após 20 dias de jejum e passaram a ser monitorados do vigésimo quinto ao trigésimo dia de jejum, quando receberam a alimentação. O monitoramento dos animais seguiu por 5 dias após a alimentação, quando finalmente foram retirados da arena.

3.3.4) Temperatura corporal: As temperaturas corporais das serpentes foram tomadas através de termômetro infravermelho (IR Thermometer Tn 2031) uma vez ao dia em horário fixo. Foram aferidas as temperaturas máximas e mínimas, sendo que foi utilizada na análise a temperatura média dos animais. O local de tomada das temperaturas corpóreas foi estabelecido como sendo o meio do corpo da serpente, assim evitando a porção cranial e caudal. A temperatura corporal foi definida após a calibração do termômetro infravermelho, através do cálculo de uma reta de regressão, prévia ao experimento, aonde foram plotadas as temperaturas cloacais e as da pele dos animais. 
3.3.5) Temperaturas escolhidas: Através da análise das imagens foi determinado o tempo de permanência dos animais em cada quadrante da arena. O cálculo da temperatura média ponderada diária foi feita da seguinte forma:

$T^{\circ} \mathbf{C}=\Sigma\left(t^{\circ} c q \cdot x[t \beta X 100 / t \alpha]\right)$

Onde:

$\mathrm{T}^{\circ} \mathrm{C}$, é a média ponderada das temperaturas procuradas pelo animal diariamente.

$\mathrm{t}^{\circ} \mathrm{cq}$, é a temperatura do quadrante onde o animal esteve.

t $\beta$, é o tempo de permanência no quadrante onde o animal esteve.

t $\alpha$, é o tempo de permanência total do animal nos diferentes quadrantes.

Considerou-se como permanência no quadrante quando o tempo em um mesmo quadrante foi superior a 4 minutos. As trocas térmicas eventualmente ocorridas durante o deslocamento das serpentes na arena foram desconsideradas.

3.3.6) Cálculo da Tset: A Tset foi definida como o intervalo térmico obtido entre o primeiro e o terceiro quartil das temperaturas procuradas durante o período de jejum, ou seja, entre os extremos máximos e mínimos aonde $50 \%$ das temperaturas procuradas foram encontradas, assim como preconizada em Hertz et al, (1993).

3.3.7) Análise estatística: A análise estatística foi feita através das regressões lineares de cada animal durante seus dias jejunos e pós-prandiais. Assim sendo cada animal possui uma reta pré-alimentar e uma pós-alimentar cujas inclinações $(\beta)$ foram comparadas entre si, para a determinação de uma tendência temporal. $O$ intercepto $(\alpha)$ e o erro padrão associados à reta do animal em jejum foram comparados ao intercepto e os erros associados à reta feita 
após a alimentação, através de teste t não pareado, para a detecção individual da diferença térmica pré e pós-alimentar. Para a determinação da reposta termofílica foi utilizado o teste de sinais associado ao resultado obtido pelos testes $\mathrm{T}$ anteriores. Assim foi possível comparar individualmente cada um dos animais para a presença ou não de uma resposta termofílica, bem como comparar entre os diferentes grupos alimentares as diferentes respostas termofílicas. Foram utilizados os programas Prisma 4.0 e Graph Pad Instat 5 para a realização dos testes estatísticos e a tabela 24 b contida em (Zar, 1999). Para todos os testes estatísticos o nível de significância foi de $\mathrm{p}<0,05$.

\section{4) Resultados:}

3.4.1) Calibragem do termômetro infravermelho: Os resultados obtidos para a calibragem do termômetro infravermelho seguem na seguinte equação: $\mathbf{T c}=\mathbf{T s}+\mathbf{3 . 9 0 4}$ / $1.073(\mathrm{p}<0.05$, Fig 3.2).

Aonde:

Tc $=$ Temperatura cloacal

Ts $=$ Temperatura da pele 
Figura 3.2: Calibragem do termômetro infravermelho. $O$ eixo $X$ representa as temperaturas cloacais em graus Celsius, o eixo Y representa as temperaturas da pele em graus Celsius.

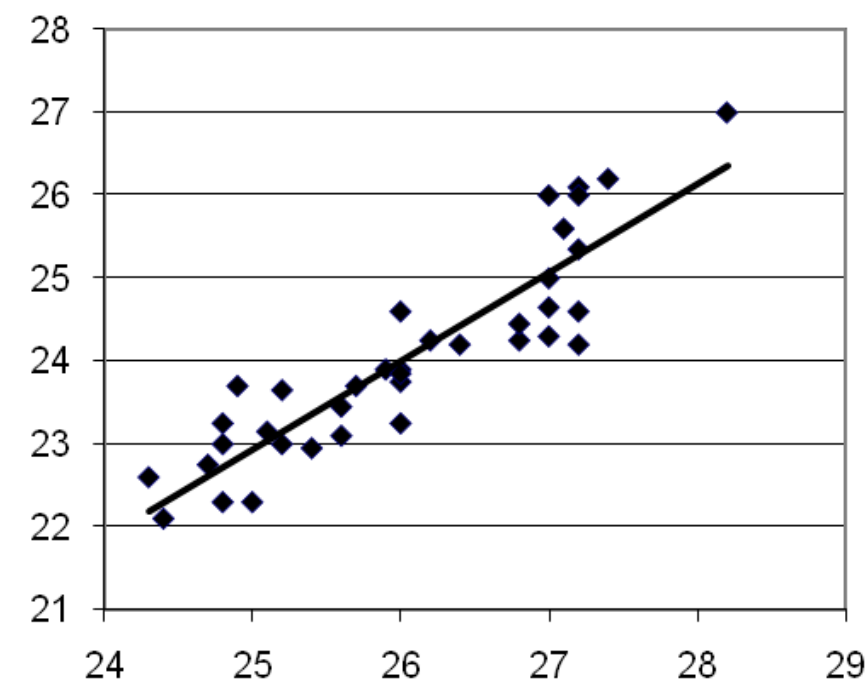

3.4.2) Temperatura preferencial: As temperaturas corporais assim como as temperaturas procuradas pelos animais foram significativamente influenciadas pelo período de atividade $(\mathrm{p}<0,001$ e $\mathrm{p}<0,0001$ respectivamente). Porém, nenhuma diferença significativa foi detectada entre os sexos, tanto nas temperaturas corporais $(p=0,055)$ quanto nas temperaturas procuradas $(\mathrm{p}=0,2974)($ Tab.3.1 e Tab.3.2). 
Tabela 3.1: Médias, desvios padrões e amplitude das temperaturas corporais e procuradas em ambas as fotofases para ambos os sexos.

\begin{tabular}{|c|c|c|c|c|c|}
\hline & Período & Sexo & Média \pm SD & Mínima & Máxima \\
\hline \multirow{5}{*}{ 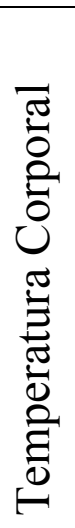 } & \multirow{3}{*}{ 音 } & $\hat{0}$ & $20,72 \pm 2,23^{\circ} \mathrm{C}$ & $15,00^{\circ} \mathrm{C}$ & $24,00^{\circ} \mathrm{C}$ \\
\hline & & & & & \\
\hline & & t & $22,00 \pm 2,09^{\circ} \mathrm{C}$ & $18,30 \mathrm{C}$ & 30,00 C \\
\hline & \multirow[b]{2}{*}{$\begin{array}{l}\text { O } \\
\text { 总 } \\
\text { Z }\end{array}$} & $\hat{0}$ & $26,62 \pm 2,19^{\circ} \mathrm{C}$ & $23,00^{\circ} \mathrm{C}$ & $34,00^{\circ} \mathrm{C}$ \\
\hline & & q & $24,5 \pm 2,20^{\circ} \mathrm{C}$ & $21,00^{\circ} \mathrm{C}$ & $29,50^{\circ} \mathrm{C}$ \\
\hline \multirow{4}{*}{ 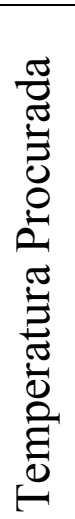 } & \multirow[b]{2}{*}{ 咅 } & $\hat{0}$ & $21,51 \pm 2,05^{\circ} \mathrm{C}$ & $16,00^{\circ} \mathrm{C}$ & $25,50^{\circ} \mathrm{C}$ \\
\hline & & q & $21,88 \pm 1,99^{\circ} \mathrm{C}$ & $17,50^{\circ} \mathrm{C}$ & $30,00^{\circ} \mathrm{C}$ \\
\hline & \multirow[b]{2}{*}{$\begin{array}{l}\text { O } \\
\text { 总 } \\
\text { z }\end{array}$} & $\hat{0}$ & $23,79 \pm 2,89^{\circ} \mathrm{C}$ & $18,00^{\circ} \mathrm{C}$ & $32,00^{\circ} \mathrm{C}$ \\
\hline & & q & $23,61 \pm 2,58$ & $20,00^{\circ} \mathrm{C}$ & $31,50^{\circ} \mathrm{C}$ \\
\hline
\end{tabular}


Tabela 3.2: Temperaturas preferenciais (Tset) e o intervalo de $50 \%$ das temperaturas corporais tomadas.

\begin{tabular}{|l|l|l|l|}
\hline & Período & Limite mínimo $(25 \%)$ & Limite máximo (75\%) \\
\hline \multirow{2}{*}{ Tset } & Diurno & $20,93^{\circ} \mathrm{C}$ & $22,20^{\circ} \mathrm{C}$ \\
\cline { 2 - 4 } & Noturno & $22,81^{\circ} \mathrm{C}$ & $24,42^{\circ} \mathrm{C}$ \\
\hline $\begin{array}{l}\mathrm{T}^{\circ} \mathrm{C} \text { corporais } \\
\text { intermediáriass } \\
(50 \%)\end{array}$ & Diurno & $20,75^{\circ} \mathrm{C}$ & $22,00^{\circ} \mathrm{C}$ \\
\cline { 2 - 4 } & Noturno & $25,00^{\circ} \mathrm{C}$ & $26,12^{\circ} \mathrm{C}$ \\
\hline
\end{tabular}

\subsection{3) Termofilia pós-prandial:}

a) Temperatura corporal: A temperatura corporal tomada durante os 5 dias pós-prandiais não mostraram variação estatisticamente significante $(\beta=0)$ em nenhum dos grupos alimentares (fig.3.2). A temperatura corporal dos animais após a alimentação também não variou significativamente frente às diferentes proporções de ingesta $\left(\beta=0, \alpha^{\prime} \mathrm{s}=\right.$ entre si, $\mathrm{p}>0,05)$. 
Figure 3.2: A, B e C representam as retas dos animais alimentados com 10, 20 e $40 \%$ respectivamente, durante 0 dia. D, E e F representam as retas dos animais alimentados com 10,20 e $40 \%$ durante 0 período noturno. $\mathrm{O}$ eixo $\mathrm{x}$ marca os dias pós-prandiais e o eixo y marca a temperatura em graus Celsius. Note que em todas as retas $\beta=0$, ou seja, não houve diferença na média das temperaturas procuradas durante os 5 dias pós-prandiais em nenhum dos grupos.
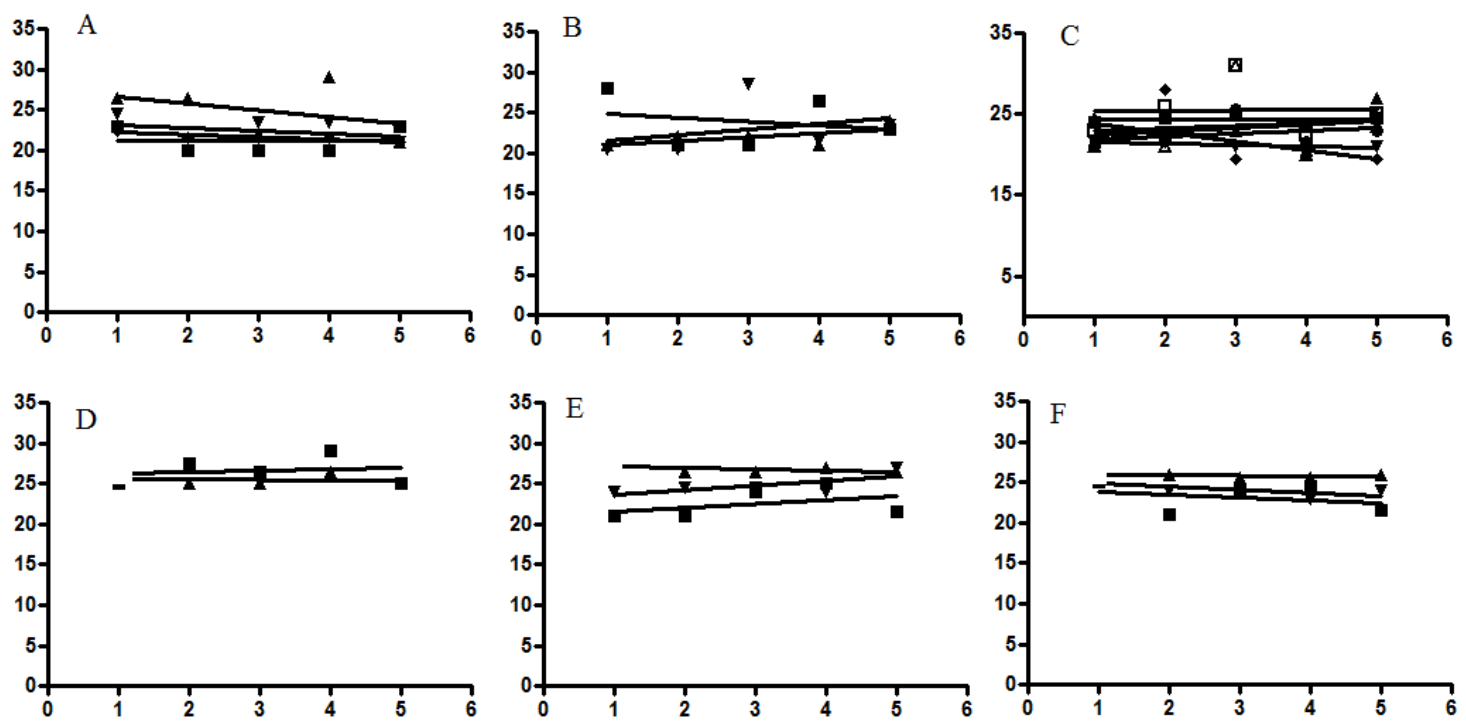

b) Resposta termofílica: A resposta termofílica pós-prandial foi baseada na diferença das temperaturas procuradas para cada animal, durante as fases pré e pós-prandial. Como não houve diferença significativa nas temperaturas escolhidas durante os 5 dias pós-prandiais $(\beta=0)$ para nenhum dos animais, foi possível comparar diretamente seus $\alpha$ 's pré e pósprandiais e os erros associados. A termofilia foi positiva em todos os grupos durante o dia, mas apenas no grupo C durante a noite (fig.3.3 e tab.3.3). 
Figura 3.3: Resultado do teste de sinais, demonstrando uma resposta termofílica positiva em todos os grupos alimentares durante o dia, porém só no grupo que alimentou-se com $10 \%$ do próprio peso durante o período noturno.

\section{Diurno}

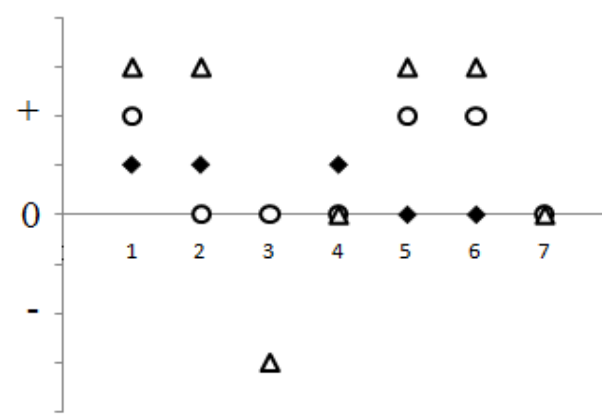

\section{Noturno}

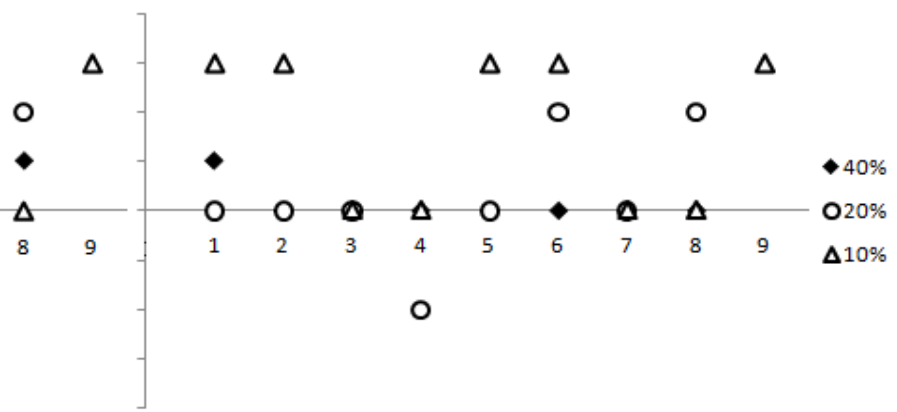

Tabela 3.3: Diferencial das temperaturas procuras pelos animais $\left(\Delta t=T^{\circ} \mathrm{C}\right.$ pós-prandial- $\mathrm{T}^{\circ} \mathrm{C}$ jejum). Em negrito os diferenciais de temperaturas dos grupos estatisticamente significantes $(\mathbf{p}<0,05)$

\begin{tabular}{|l|l|l|l|}
\hline & $\mathrm{A}$ & $\mathrm{B}$ & $\mathrm{C}$ \\
\hline Diurno & $\mathbf{2 , 6 5}^{\circ} \mathbf{C}$ & $\mathbf{2 , 0 0}^{\circ} \mathbf{C}$ & $\mathbf{3 , 1 3}^{\circ} \mathbf{C}$ \\
\hline Noturno & $-0,88^{\circ} \mathrm{C}$ & $0,19^{\circ} \mathrm{C}$ & $2,25^{\circ} \mathrm{C}$ \\
\hline
\end{tabular}




\section{5) Discussão:}

3.5.1) Temperatura preferencial : A Tset representa o intervalo térmico de ótima performance fisiológica das serpentes e suas variações entre as diferentes famílias e grupos parecem ser decorrentes de uma complexa trama de características comportamentais, filogenéticas, sazonais e até mesmo embrionárias (Hertz et al, 1993; Blouin-Demers et al, 2000; Beaupre, 2002).

Serpentes noturnas, pouco ativas e de alimentação infreqüente apresentam geralmente faixas térmicas menores que as demais, todavia, isso não parece afetar o fitness destes animais (Shine et al, 2003). As Bothrops moojeni utilizadas no experimento apresentaram uma Tset próxima a outras faixas térmicas preferenciais obtidas para diferentes serpentes crotalinae (Mori, 2002). Tal qual a maioria dos outros crotalinae Bothrops moojeni é considerada essencialmente noturna, pouco ativa e caçadora de emboscada, o que exerce uma grande influência nas temperaturas procuradas por estes animais (Campbell \& Lamar, 2004).

A associação entre a temperatura e o consumo energético nas serpentes torna a escolha térmica durante a inatividade especialmente importante para as espécies pouco ativas (Webb \& Shine, 1998; Whitaker \& Shine 2002; Llewelyn et al, 2005). A busca de B.moojeni por temperaturas mais baixas durante o dia sugere que a economia no consumo de energia durante a inatividade é importante nestes animais, todavia, generalizações devem ser cautelosas visto que outros crotalinae noturnos pouco ativos como Trimeresurus stejnegeri não demonstraram nenhum efeito do período de atividade sobre a seleção de 
temperaturas no gradiente térmico (Tsai \& Tu, 2005). No caso de T.stejnegeri, segundo os autores, a ausência de diferença entre as temperaturas durante a atividade e a inatividade seria devido à desnecessidade de caçadores de espreita manterem temperaturas mais altas durante a sua atividade. Os resultados obtidos com B.moojeni e T.stejnegeri sugerem distintas temperaturas ótimas de atividade entre estas espécies. Porém, durante a inatividade, a média térmica encontrada para T.stejnegeri $\left(22,5 \pm 1^{\circ} \mathrm{C}\right)$ é bastante próxima da faixa preferencial de B.moojeni.

As estratégias termorregulatórias durante a atividade variam bastante entre as diferentes serpentes. Algumas espécies preponderantemente noturnas parecem termorregular ativamente durante alguns períodos do dia, através de manobras similares às dos animais diurnos, expondo-se ao Sol (Ayers \& Shine, 1997; Llewelyn, 2005). Outras espécies parecem ser extremamente termoconformadoras, mesmo diante da possibilidade termorregulatória no cativeiro (Shine \& Madsen, 1995), mantendo muitas vezes a mesma temperatura durante o dia e a noite (Slip \& Shine, 1988b, Lutterschimdt \& Hutchison, 2003; Tsai \& Tu, 2005). Os resultados obtidos em nosso experimento demonstraram que B.moojeni buscou quadrantes de temperaturas mais elevadas durante a noite, numa manobra claramente termorregulatória. Resultados similares a este padrão de escolha térmica já foram registrados em alguns elapídeos noturnos australianos (Llewelyn et al, 2005). A procura por temperaturas mais elevadas durante a atividade parece aumentar as chances de sucesso na captura de presas e a habilidade defensiva dos animais, visto que foi demonstrado que performances fisiológicas como a capacitação dos órgãos dos sentidos e a velocidade de reação frente a uma agressão são termodependentes (Avery et al, 1982; Hertz 
et al, 1982; Hertz et al, 1988; Stevenson et al, 1985; Ayers \& Shine 1997, Shine et al, 2002; Chen et al, 2003).

Mudanças de faixas de Tset durante o crescimento podem ocorrer em diferentes espécies, pois o tamanho dos animais é outro fator limitante nos coeficientes de troca térmica, assim como nas diferentes necessidades energéticas (McNab \& Auffberg, 1976; Grigg et al, 1979; Ayers, 1992; Shine \& Madsen, 1995; Seebacher et al, 1999). Essas mudanças ontogenéticas de Tsets podem estar até mesmo associadas a mudanças no período de atividade dos animais (Slip \& Shine, 1988c). Todavia, a interpretação destes dados deve ser feita com cautela, pois mudanças no período de atividade em campo podem significar uma maior necessidade ecológica de manter a temperatura mais próxima da faixa fisiológica ótima em determinada fase da vida, mudanças primárias de dieta ou no tipo de pressão de predação sobre os animais e não uma efetiva mudança ontogenética das temperaturas preferenciais (Ayers \& Shine, 1997).

As diferenças entre as temperaturas de atividade de machos e fêmeas é outro ponto razoavelmente discutido, entretanto parece não existir uma resposta única entre as diferentes espécies (Slip \& Shine, 1988a). Temperaturas mais baixas acessadas pelos machos durante determinadas fases do ano parecem estar relacionados à espermiogênese (Herczeg et al, 2007) temperaturas mais elevadas estão quase sempre relacionadas a fêmeas prenhes (Shine, 1979; Slip \& Shine, 1988a; Luiselli \& Zimmermann, 1997; Luiselli \& Akani, 2002), ainda que temperaturas preferenciais mais baixas para fêmeas prenhes também já tenham sido documentadas (Sanders \& Jacob, 1981; Isaac \& Gregory, 2004). Nosso trabalho não demonstrou diferença nas temperaturas preferenciais procuradas por 
machos e fêmeas. No entanto, não podemos descartar que esta ausência de diferença pode estar ligada a uma homogeneidade do tamanho dos animais utilizados no experimento.

A sazonalidade é outro fator marcante nas temperaturas acessadas pelos animais na natureza e sua variação pode não só estar ligada a diferença das temperaturas disponíveis, mas também a uma mudança sazonal das próprias temperaturas preferenciais (Shine \& Lambeck, 1985; Ladyman et al, 2006). Entretanto o presente trabalho não detectou diferença significativa nos resultados obtidos ao longo do ano, o que provavelmente reflete as condições homogêneas de manutenção durante todo o experimento.

3.5.2)Termofilia pós-prandial: A resposta termofílica pós-prandial é um fenômeno que foi documentado em várias espécies de serpentes (Regal, 1966; Lysenko \& Gillis, 1980; Slip \& Shine, 1988b; Jaeger\& Garbor, 1993; Sievert \& Andreadis, 1999; Sievert et al, 2005; Tsai \& Tu, 2005) e, embora de ampla ocorrência, alguns animais parecem efetivamente não apresentá-la (Tu \& Hutchinson, 1995). Os dados do presente trabalho apontam para Bothrops moojeni como uma espécie que pode apresentar resposta termofílica pós-prandial. Entretanto, é necessário observar que a resposta termofílica parece ser multifatorial, já que diversos graus de resposta termofílica foram vistos para as diferentes proporções alimentares consumidas pelos animais, sendo que esta resposta foi efetivamente maior durante o período de inatividade.

A relação entre a resposta termofílica e o período de atividade dos animais é complexa, já que a detecção depende da diferença das temperaturas pós-prandiais e durante o jejum nos dois períodos. A resposta termofílica já foi detectada em ambos os períodos em animais 
cujas temperaturas procuradas são similares durante o dia e durante a noite (Slip \& Shine, 1988b, Tsai \& Tu, 2005). Porém, em nosso experimento, as temperaturas procuradas por B.moojeni no jejum variaram conforme o fotoperíodo. Durante o dia temperaturas mais baixas procuradas pelas serpentes em jejum podem não ter sido satisfatórias durante a digestão dos animais, nesse caso, após a alimentação foi notória a resposta termofílica. Entretanto, durante a noite os animais jejunos procuraram temperaturas maiores para a realização de suas atividades e esta faixa de temperatura não divergiu significativamente das temperaturas procuradas após a alimentação na maioria dos animais, assim sendo, ainda que a grande maioria dos animais tenha apresentado uma resposta termofílica diurna, apenas alguns deles apresentaram esta mesma resposta termofílica durante a noite.

A resposta termofílica pós-prandial também parece ser dependente da quantidade de alimento ingerido, mas infelizmente os dados individuais sobre a porcentagem de alimento ingerida por cada animal não estão disponíveis em muitos trabalhos (Slip \& Shine, 1988b). Em nosso estudo a resposta termofílica em ambos os períodos só ocorreu para animais que comeram as proporções alimentares de $10 \%$ de seu próprio peso. A explicação para ausência da resposta termofílica noturna nos animais que comeram proporções maiores de alimento $(20 \%$ ou $40 \%)$ parece estar ligada à reposta termogênica que ocorre durante a digestão (SDA), que é sabidamente maior em animais que ingeriram proporções alimentares maiores (Andrade et al, 1997; Tattersall et al, 2004). A ausência de diferença nas temperaturas corporais pós-prandiais entre os grupos corrobora com a importância da termogênese pós-prandial na manutenção de temperaturas pós-prandiais.

A variação individual na resposta termofílica em Bothrops moojeni e mesmo os diferentes resultados encontrados na literatura indicam que a importância da termofilia pós-prandial 
varia muito entre as espécies e as diferentes condições encontradas pelos animais na natureza. No futuro novas pesquisas que dimensionem as necessidades térmicas e a implicação ecológica e fisiológica da manutenção da temperatura poderão esclarecer um pouco mais este complexo ponto de discussão que rege a vida dos ectotermos.

\section{Bibliografia:}

Andrade, D. V.; Cruz-Neto, A. P.; Abe, A. S. (1997). Meal size and specific dynamic action in the rattlesnake Crotalus durissus durissus (Serpentes: Viperidae). Herpetologica $53,485-493$.

Angilletta, M. J.; Niewiarowski, P. H.; Navas, C.A. (2002). The evolution of thermal physiology in ectotherms. J. Therm. Biol. 27:249-68.

Avery, R. A. (1982). Field studies of body temperatures and thermoregulation. Pp 93-166 in Gans, C. and Pough, H. F., eds. Biology of Reptilia v.12. Physiology C. Physiological ecology. Academic press. New York

Avery, R. A.; Bedford, J. D.; Newcombe, C.B. (1982). The role of thermoregulation in lizards biology: Predatory efficiency in a temperate diurnal baskers. Behaviour Ecology and Sociobiology 11, 261-267.

Ayers, D. Y. (1992). Effect ofbody size and posture on the thermal biology of diamond pythons, Morelia spilota spilota, (Serpentes: Boidae). Honours thesis. University. of Sydney Australia 
Ayers, D.Y.; Shine, R. (1997). Thermal influences on foraging ability: body size, posture and cooling rate of an ambush predator, the python Morelia spilota. Functional Ecol. $11,342-347$.

Barber, B.J.; Crawford, E.C. (1977). A stochastic dual-limit hypothesis for behavioral thermoregulation in lizards. Physiol. Zool. 50, 53-60.

Bartholomew, G. A. (1982). Physiological control of body temperature. In Gans, C. and Pough, F. H. (Eds): Biology of the Reptilia, Vol. 12: Physiological Ecology, pp. 167-211. Academic Press, New York, NY.

Beaupre, S. J. (2002). Modeling time-energy allocation in vipers: Individual response to environmental variations and implication for population. In Schuett G. W.; Hoggren M.; Douglas M. E. And Greene H. W. In Biology of the Vipers, pp 463-481, Eagle Mountain Publishing, Eagle Mountain, UT.

Blouin-Demers, G.; Kissner, K. J.; Weatherhead P. J. (2000). Plasticity in preferred body temperature of young snakes in response to temperature during development. Copeia $3,841-845$.

Bogert, C. M. (1949). Thermoregulation in reptiles: a factor in evolution. - Evolution 3: 195-211.

Bogert, C. M. (1959). How reptiles regulate their body temperature. - Scientific American 22: $213-221$.

Brattstorm, B. H. (1965). Body temperatures of reptiles. Am. Midl. Nat. 73, 376-422.

Brown G.P.; Weatherhead, P.J. (2000). Thermal ecology and sexual size dimorphism in northern water snakes, Nerodia sipedon. Ecol. Mon. 70:311-30. 
Campbell, J. A. \& Lamar W. W. (2004). In Venomous of the western hemisphere, vol 1, Cornell Univers, Press,, Ithaca, New York

Carpenter, C. C. (1956). Body temperature of three species of thamnophis. Bull. Eco. Soc. Am. 36, 74.

Chen X.; Xu X.; Ji, X. (2003). Influence of body temperature on food assimilation and locomotor performance in whitestriped grass lizards, Takydromus wolteri (Lacertidae). J. Therm. Biol. 28:385-91.

Cowles, R. B. \& Bogert, C. M. (1944). A preliminary study of thermal requirements of desert reptiles. Bull. Am. Mus. Nat. Hist. 83, 261-296.

Daltry, J. C.; Ross T.; Thorpe R. S.; Wuster W. (1998). Evidence that humidity influences snake activity patterns: a field study of Malayan pit viper Calloselasma rhodostoma. Ecography, vol 21, pp 25-34.

Gibson, A. R. \& Falls, J. B. (1979). Thermal biology of the common garter snake Tamnophis sirtalis (L.). Temporal variation, environmental effect and sex difference. Oecologia (Berlin) 43, 79-97.

Gibson, A. R.; Smucny, D. A.; Kollar, J. (1989). The effects of feeding and ecdysis on temperature selection by young garter snakes in a simple thermal mosaic. Canadian Journal of Zoology 67: 19-23.

Greenwald, O. E. \& Kanter M. E. (1979). The effects of temperature and thermorregulation on digestive efficiency in corn snakes: Elaphe guttata guttata. Physiol. Zool. 52, 398-408. 
Grigg, G. C.; Drane, C. R.; Courtice, G. P. (1979). Time constants of heating andcooling in the eastern water dragon,Physignathus lesueurii and some generalisations aboutheating andcooling in reptiles. J. Therm. Biol. 4, 95-103.

Gvozdik, L. (2002). To heat or to save time? Thermoregulation in the lizard Zootoca vivipara (Squamata: lacertidae) in different thermal environments along an altitudinal gradient. Can. J. Zool. 80:479-492.

Heath, J. E. (1964). Reptilian thermorregulation: evaluation of field studies. Science (Washington, D.C) 146, 784-785.

Heath, J. E. (1970). Behavioral thermoregulation of body temperatures in poikilotherms. Physiologist 13: 399-410.

Herczeg, G.; Saarikivi, J.; Gonda, A.; Perala, J.; Tuomola, A.; Merila, J. (2007). Subotimal thermoregulation in male adders (Vipera Berus) after hibernation imposed by spermiogenesis. Biological Journal of Linnean Society, 92: 19-27

Hertz, P. E (1974). Thermal passivity of a tropical forest lizard, Anolis polylepis. J. Herpetol., 8: 323-327.

Hertz, P. E.; Huey, R. B.; Nevo, E. (1982). Fight versus flight: thermal dependence of defensive behaviour in a lizard. Anim Behav 30:676-9.

Hertz, P. E.; Huey, R. B,; Garland T. (1988). Time budgets, thermoregulation and maximal locomotor performance: are reptiles Olympians or boy scouts? Amer. Zool. 28:927-38.

Hertz, P. E (1992). Evaluating thermal resources partitioning by sympatric Anolis cooki and A. cristatellus: a field test using null hipotheses. Oecologia (Berlin) 90: 127-136. 
Hertz, P. E.; Huey, R. B.; Stevenson, R. D.(1993). Evaluating Temperature Regulation by Field-Active Ectotherms: The Fallacy of the Inappropriate Question The American Naturalist, Vol. 142, No. 5. (Nov., 1993), pp. 796-818

Huey, R. B. (1974). Behavioral thermoregulation in lizards: importance associated cost. Science (Washington, D.C) 184: 1001-1003.

Huey, R. B.; Slatkin, M. (1976). Cost and Benefits of Lizard Thermoregulation. The Quarterly Review of Biology, Vol. 51, No. 3 pp. 363-384.

Huey, R. B.; Pianka, E. R.; Hoffman, J. A. (1977). Seasonal variation in thermoregulatory behavior an body temperature of diurnal Kalahari lizards. Ecology 58: 1066-1075.

Huey, R. B. (1982). Temperature physiology and ecology of reptiles. In Biology of Reptilia. (Edited by Gans C. and Pough F. H.), vol 12, pp 25-91. Academic press, London.

Huey, R.B.; Hertz, P.E. (1984). Is a jack-of-all-temperatures a master of none? Evolution $38,441-444$.

Hutchinson, V. H. \& Dupré R. K. (1992). Thermoregulation. Pp 206-249. In M. F. Feder and W. W. Burggren, eds. Environmental physiology of the amphibians. University of Chicago press. Chicago.

Isaac, L. A.; Gregory, P. T.; (2004). Thermoregulatory behavior of gravid and non-gravid female grass snake (Natrix natrix) in a thermally limiting high altitude environment. $J$. Zoo., Lond. 264, 403-409.

Jaeger, R. B. \& Garbor, C. R. (1993). Postprandial thermophily in rough green snakes (Opheodrys aestivus). Copeia 4, 1174-1776. 
Lailvaux, S. P.; Alexander, G. J.; Whiting, M. J. (2003). Sex-based differences and similarities in locomotor performance, thermal preferences and escape behaviour in the lizard Platysaurus intermedius wilhelmi. Phys. Biochem. Zool. 76:511-21.

Ladyman, M.; Bradshaw, D.; Bradshaw, F (2006). Physiological and hormonal control of thermal depression in Tiger Snake, Notechis scutatus. J. Comp. Physiol B 176, 547-557.

Llewelyn, J.; Shine, R.; Webb, J. K. (2005). Thermal regimes and diel activity patterns of four species of small elapid snakes from southeastern Australia. Aust. J. Zool. 53, 1-8.

Licht, P.; Dawnson, W. R.; Shoemaker, V. H.; Main, A. R.(1966). Observation on the thermal relation of western Australian lizard. Copeia 1966/ 97-110.

Licht, P.(1967). Thermal adaptation in the enzymes of lizard in relation to preferred body temperature. Pp 131-145 un C. L. Prosser, ed. Molecular machanisms of temperature adaptation. American Association for the Advancemente of science. Washington, D.C Lillywhite H. B. (1987). Temperature, energetics, and physiological ecology. In snakes: Ecology and Evolutionary Biology. (Edited by Seigel R. A.; Collins J. T. And Novak S. S.), pp 422-477. Macmillan, New York.

Luiselli, L.; Akani, G. C. (2002). Is thermoregulation really unimportant for tropical reptiles? Comparative study of four sympatric snake species from Africa. Acta Oecologica $2359-68$.

Luiselli, L.; Zimmermann, P. (1997). Thermal ecology and reproductive cyclicity of the snake Natrix tessellata in south-eastern Austria and central Italy: A comparative study. Amphib. Reptil. 18, 383-396.

Lutterschimdt, D \& Hutchinson, P. (2003). Influence of thyroid on the thermal selection of African hous snakes (Lamprophis fuliginosos)Journal of thermal biology 28, 167-173. 
Lysenko, S. \& Gillis, J. E. (1980). The effect of ingestive status on thermorregulatory behavior of Thamnophis sirtalis sirtalis and Thamnophis sirtalis parietalis. J. Herpetol. 14, 155-159.

McGinis, S. M. (1970). Flexibility of thermoregulatory behavior in the western fence lizard Sceloporus occidentalis. Herpetologica 26: 70-76.

McNab, B. K \& Auffeberg, W. (1976). The effect of large body size on temperature regulation of the Komodo dragon, Varanus komodoensis. Comp. Biochem. Physiol. 55a, $345-350$.

Mori, A.; Toda, M.; Ota, H. (2002). Winter activity of Ovophis okinavensis in the humid subtropics: foraging on breeding frogs under cool temperature. - In: Hoggren, M. (ed.), Biology of the vipers. Uppsal Peterson, C. R

Naulleau G. (1983). The effects of temperature on digestion in Vipera aspis. J. Herpetol. $16,166-177$.

Regal, P. J. (1966). Thermophilic response following feedingin certain reptiles. Copeia $1966,588-590$.

Rosen, P. C. (1991). Comparative field study of thermal preferenda in Garter snakes (Thamnophis) Journal of Herpetology 25: 301-312.

Sanders, J. S. \& Jacob, J. S. (1981). Thermal ecology of the copperhead (Agkistrodon contortrix). Herpetologica 37(4): 264- 270.

Seebacher, F.; Grigg, G. C.; Beard, L.A. (1999). Crocodiles as dinosaurs: behavioural thermoregulation in very large ectotherms leads to high and stable body temperatures. $J$. Exp. Biol. 202, 77-86. 
Shine, R. (1979). Activity pattern in Australian elapid snake (squamata:Serpente:Elapidae), Herpetologica, vol 35, pp 1-11.

Shine, R. \& Lambeck, R. (1985). A radiothelemetric study of movements, thermorregulation and habitat utilization of Arafura filesnake (Serpentes: Acrochordidae), Herpetologica, 41: 351 .

Shine, R. (1987). Intraespecific variation in thermoregulation, movements and habitat use by Australian blacksnake Pseudechis porphyriacus (Elapidae), J. Herpetology 21, 165-177. Shine R, Madsen, T. (1995). Is thermoregulation unimportant for most reptiles? An example using water pythons (Liasis fuscus) in tropical Australia. Physiological Zoology 69 (2): 252-269.

Shine, R.; Sun, L.; Fitzgerald, M.; Kearney, M. (2002). Behavioral responses of freeranging pit-vipers (Gloydius shedaoensis, Viperidae) to approach by a human. - Copeia 2002: 843-850.

Shine, R.; Sun, L.; Fitzgerald, M.; Kearney, M. (2003). A radiotelemetric study of movements and thermal biology of insular Chinese pit-vipers (Gloydius shedaoensis, Viperidae), Oikos 100, 342-352.

Sievert, L. M. \& Andreadis, P. (1999). Specific dynamic action and postprandial thermophily in juvenile northern water snakes, Nerodia sipedon. J. Thermal biology, vol $24,51-55$.

Sievert L. M.; Jones D. M.; Puckett M. W. (2005). Postprandial thermophily, transit rate and digestive efficiency of juvenile cornsnake, Pantherophis guttatus. J. Thermal biology, vol 30, pp 354-359. 
Slip, D. J. \& Shine, R. (1988a). Reptilian endothermy: A field study of thermoregulation by brooding diamond pythons. J. Zool., London 216, 367-378.

Slip, D. J. \& Shine, R. (1988b). Thermophilic response to feeding of the diamond python, Morellia s. spilota (Serpentes, Boidae). Comp.Biochem.Physiol. vol 89a, n 4, pp 645-650.

Slip, D. J. \& Shine, R. (1988c). Feeding habbits of the diamond python, Morellia s. spilota ambush predation by a boid snake. Journal of Herpetology, 22, 321-328.

Stevenson, R. D. (1985a). Body size and limits to the daily range of body temperature in terrestrial ectotherms. American Naturalist 125: 102-117.

Stevenson, R. D. (1985b). The relative importance of behavioral and physiological adjustments controlling for body temperature in terrestrial ectotherms. American Naturalist 126: $362-386$

Stevenson, R. D.; Peterson, C. R.; Tsuji, J. S. (1985). The thermal dependcence of locomotion, tongue flicking, digestion, and oxygen consumption in the wandeinrg garter snake. Physiol. Zool. 58:46- 57.

Tattersall G, J,; Milson W, K,; Abe, A, S,; Brito S, P,; Andrade D, V, (2004) The thermogenesis of digestion in rattlesnakes, J, Exp, Biol,, vol, 207, pp 579-585,

Toledo, L. F.; Abe, A. S. \& Andrade D. V. (2003). Temperature and meal size effects on the postprandial metabolism and energetics in a Boid snake. Physiological and Biochemical Zoology, 76(2):240-246.

Tsai, T.-S \& Tu, M.-C (2005). Postprandial thermophily in Chinese green tree vipers, Trimeresurus stejnegeri stejnegeri: inferring factors on snake temperature selection in a thigmothermal gradient. Journal of thermal biology 30, 423-430. 
Tu, M.-C.; Hutchinson, V. H.,(1995). Lack of postprandial thermophily in diamond back water snakes, Nerodia rhombifera. Comp. Biochem. Physiol. 110A,21-25.

Van Damme, R.; Bauwens, D.; Verheyen, R. F. (1986). Selected body temperatures in the lizard Lacerta vivipara: variation withim and between populations. Journal of Thermal Biology 11: 219-222.

Webb, J. K. \& Shine, R. (1998). Using thermal ecology to predict retreat-site selection by an endangered snake species. Biological Conservation 86, 233-242.

Whitaker, P. B; Shine, R. (2002). Thermal biology and activity patterns of the eastern Brownsnake (Pseudonaja textilis): A radiotelemetric study. Herpetologica 58, 436-452.

Withers, P. C. \&Campbell, J. D. (1985). Effects of environmental cost on thermoregulation in the desert iguana. Physiological Zoology 58: 329-339.

Zar, J. H. (1999). Biostatistical Analysis, 4th edn. Prentice Hall Inc, Upper Saddle River, NJ. 


\section{Capítulo 4: Ritmo circadiano em Bothrops moojeni em cativeiro (Serpentes: viperidae)}

Stuginski, D. R. ${ }^{1}$; Abe, A. S. ${ }^{2}$; Fernandes, W. ${ }^{3}$

Departamento de Fisiologia do IB-USP' ${ }^{1}$, Departamento de Zoologia da Unesp-RC², Laboratório de Herpetologia do Instituto Butantan ${ }^{3}$

\subsection{1) Abstract:}

Crotalinae are considered to be mainly nocturnal and most of the gathered data on these snakes came from field work. The knowledge of activity pattern and how nutritional status affect wandering rate are determinant to understand the ecophysiology of the snakes. In this study the daily activity pattern was followed in 29 subjects of the lancehead Bothrops moojeni in order to record displacement rate in fasting and feed snakes for five days after feeding meal of 10, 20 and $40 \%$ of their own body weight. The results show that $B$. moojeni is prevalently nocturnal, and activity increased 45 times at night, peaking between 19 to 20 $\mathrm{h}$, in both males and females. Activity level changed significantly after feeding in snakes which ate a larger meal $(20-40 \%)$. The results confirm previous field data for B.moojeni as a nocturnal species with low mobility. The complex interactions between the amount of food taken by the snake, energetic balance and mobility are discussed.

Key words: Bothrops moojeni, activity pattern, post-prandial, circadian rhythms 


\subsection{2) Resumo:}

As serpentes crotalinae são tidas como animais preponderantemente noturnos sendo que a maioria dos dados a respeito dessas atividades foram obtidos em pesquisas de campo. A detecção do período de atividade, assim como o conhecimento de como o estado nutricional influencia a taxa de trânsito, são extremamente importantes na compreensão da ecofisiologia destes animais. No estudo foram utilizadas 29 exemplares de Bothrops moojeni, monitoradas quanto ao horário e o tempo de deslocamento durante o jejum e nos 5 dias subseqüentes a alimentação. A alimentação das serpentes variou entre 10, 20 e 40\% do peso da própria serpente. Os resultados confirmaram Bothrops moojeni como espécie essencialmente noturna, sendo que a atividade foi aumentada em mais de 45 vezes durante o período. O pico de atividade ocorreu entre as 19:00 e 20:00 horas, não havendo diferença estatística entre machos e fêmeas. Com relação à atividade pós-prandial foi notada diferença estatística nas taxas de deslocamento dos animais que comeram as maiores proporções (20-40\%). Os resultados obtidos corroboram com os dados prévios obtidos em estudos de campo que pontuam Bothrops moojeni como um animal noturno e de baixo grau de mobilidade. A interação entre a quantidade de alimento ingerido pela serpente, o balanço energético e o grau de mobilidade dos animais é bastante complexa e discutível.

\section{2) Introdução:}

O deslocamento em serpentes, bem como o período de atividade, tem sido objeto de estudos ao longo dos anos (Gibbons \& Semlitsch, 1987; Gregory et al, 1987; Reinert, 1992; Webb \& Shine, 2006). Basicamente as serpentes se deslocam à procura por alimento, 
parceiros para acasalamento, abrigo, locais para hibernação, ou mesmo na busca de novos locais para executar todas estas atividades (Larsen et al, 1987; Macartney, 1988; Bonnet et al, 1999).

Dentre as serpentes existe uma grande diversidade de padrões de atividade, variando desde aquelas extremamente ativas, que se deslocam constantemente, até as que tendem a permanecer em um mesmo local, economizando energia, e aguardando a oportunidade de emboscar uma eventual presa (Slip \& Shine, 1988; Secor, 1994; Shine \& Fitzgerald, 1996; Daltry et al, 1998; Downes \& Shine, 1998; Angelici et al, 2000; Shetty \& Shine, 2002; Whitaker \& Shine, 2003; Shine et al 2003; Shine et al, 2004). O deslocamento, e mesmo a atividade das serpentes, podem variar bastante conforme a época do ano, a procedência dos espécimes, a idade do indivíduo, seu estado fisiológico, dentre outras variáveis (Shine, 1979; Shine 1987; Whitaker \& Shine, 2003). As serpentes são grosseiramente divididas em diurnas e noturnas, conforme seu período de atividade. Apesar disto, estas relações de período de atividade não são tão definidas, sendo que, certas serpentes apresentam atividade em ambos os períodos e outras são essencialmente crepusculares (Shine, 1979; Shine \& Lambeck, 1985)

O período de atividade e o tipo de padrão de deslocamento em serpentes do gênero Bothrops, têm sido estudados no campo e os resultados indicam que são essencialmente noturnas e crepusculares ( Hartmann et al, 2003). Estas serpentes geralmente adotam a tática "mobile ambushers" deslocando-se até encontrarem bons locais para emboscar suas presas, embora algumas espécies do gênero tenham sido vistas forrageando ativamente (Sazima, 1989, 1991; Egler 1996; Martins et al 2002). A maioria dos dados sobre deslocamento e atividade de serpentes é feita através de observações em campo, que 
embora indispensáveis para a compreensão de padrões, são insuficientes quando queremos responder questões como: Por quanto tempo estes animais se deslocam? Como o deslocamento é distribuído ao longo do período de atividade? Como estados físiológicos diferentes, como por exemplo, a condição pós-prandial, pode afetar o deslocamento destes animais?

O deslocamento, após a ingestão de grandes presas nas serpentes representa um enorme desafio, devido ao acréscimo de massa que os animais terão de mobilizar durante as suas atividades diárias (Greene, 1997; Cundall \& Greene, 2000; Branch, 2002). Um grande aumento de massa resulta diretamente num maior dispêndio energético, deslocamento mais lento e em maior risco de predação. Serpentes que se alimentam de presas grandes também demoram mais tempo para digeri-las o que significa estarem submetidas a todo este custo por um tempo prolongado (Toledo et al, 2003)

O presente trabalho foi realizado no intuito de elucidar as seguintes questões: Qual é o período de atividade de Bothrops moojeni em cativeiro? Existe diferença sexual nos períodos de deslocamento destes animais? Qual o tempo diariamente dedicado ao deslocamento? Como a quantidade de alimento ingerida pode influenciar nas taxas de deslocamento?

\section{3) Material e Métodos:}

Foram utilizados no experimento 29 exemplares de Bothrops moojeni mantidas conforme foi supracitado (Ver Capítulo 2). 
Durante os experimentos os animais foram colocados em um terrário de vidro com fundo de metal, de $180 \times 60 \times 80 \mathrm{~cm}$, (comprimento $\times$ largura $\times$ altura), com substrato de terra previamente esterilizada em estufa, a $130^{\circ} \mathrm{C}$ por 6 horas. Um gradiente térmico foi estabelecido no terrário, com o uso de um aquecedor (220v) em uma das extremidades e um resfriador Coel® (220v) na outra, de forma que temperatura dentro do terrário variou de $36^{\circ} \mathrm{C}-17^{\circ} \mathrm{C}\left( \pm 2^{\circ} \mathrm{C}\right)$.-O terrário foi dividido em 40 quadrantes de $15 \times 15 \mathrm{~cm}$, delimitados por barbantes colocados sobre a terra e presos às laterais do terrário com fita adesiva ficando rente ao substrato e não interferindo no deslocamento das serpentes. O terrário também foi dividido ao meio em seu eixo longitudinal, através de uma placa de madeirite, por toda extensão e altura do terrário, assim sendo foram formadas duas arenas com 20 quadrantes de comprimento e dois quadrantes de largura ambos com a porção inicial aquecida e a porção terminal resfriada. Em uma das arenas pequenos anteparos foram colocados sobre a terra para aferir se estes obstáculos influenciariam no deslocamento dos animais (Fig. 4.3.1).

Os 29 animais foram divididos em três grupos alimentares A, B e C, que ingeriram com 40, 20 e $10 \%$, respectivamente, de seu próprio peso em alimento (Tab.4.3.1). A cada sessão experimental foi colocada uma serpente em cada uma das arenas, ambas monitoradas através "web cam" ligada a um computador Pentium III. A captura das imagens noturnas foi feita com auxilio de "LEDs" infravermelhos próprio para filmagens na escuridão. As imagens foram feitas através de fotos tomadas automaticamente a cada 60 segundos pelo programa HSSVSS 6.06. Assim, a cada dia foram tomadas cerca de 1440 fotos, que capturaram a movimentação nas duas arenas, das duas serpentes em experimento. 
O fotoperíodo na sala dos animais foi mantido em 12:12 horas de fotofase e escotofase através de "timer" digital instalado nas lâmpadas da sala (lâmpadas Phillips fluorescentes T-12, oito lâmpadas no total). A umidade da sala foi mantida entre 56 e $70 \%$ ao longo do experimento. Após o monitoramento dos 15 primeiros animais, o fotoperíodo foi invertido de claro/escuro, para escuro/claro, mantendo-se o padrão 12:12. Os animais foram aclimatados por 30 dias sob o novo fotoperíodo, para que seus ciclos circadianos pudessem ser estabilizados antes que os 14 animais restantes fossem monitorados na arena.

Foi considerado como deslocamento todo trânsito da serpente que durasse mais de 4 minutos, assim, pequenas movimentações e ajustes de posição não foram computados durante as medidas. Após um período de 5 dias de adaptação na arena os animais que já estavam em jejum a 25 dias foram monitorados por 5 dias pré-alimentares e mais 5 dias após a alimentação. Os tempos de movimentação, bem como o momento da noite quando esta movimentação ocorreu, foram analisados, assim como a influência do sexo e do estado pós-prandial dos animais. Para a análise estatística utilizamos os testes T e Kruskal Wallis, e o nível de significância para os testes executados foram de 0,05 . 
Figura 4.3.1: Arena com anteparos durante a fotofase, arena sem anteparos durante a escotofase.

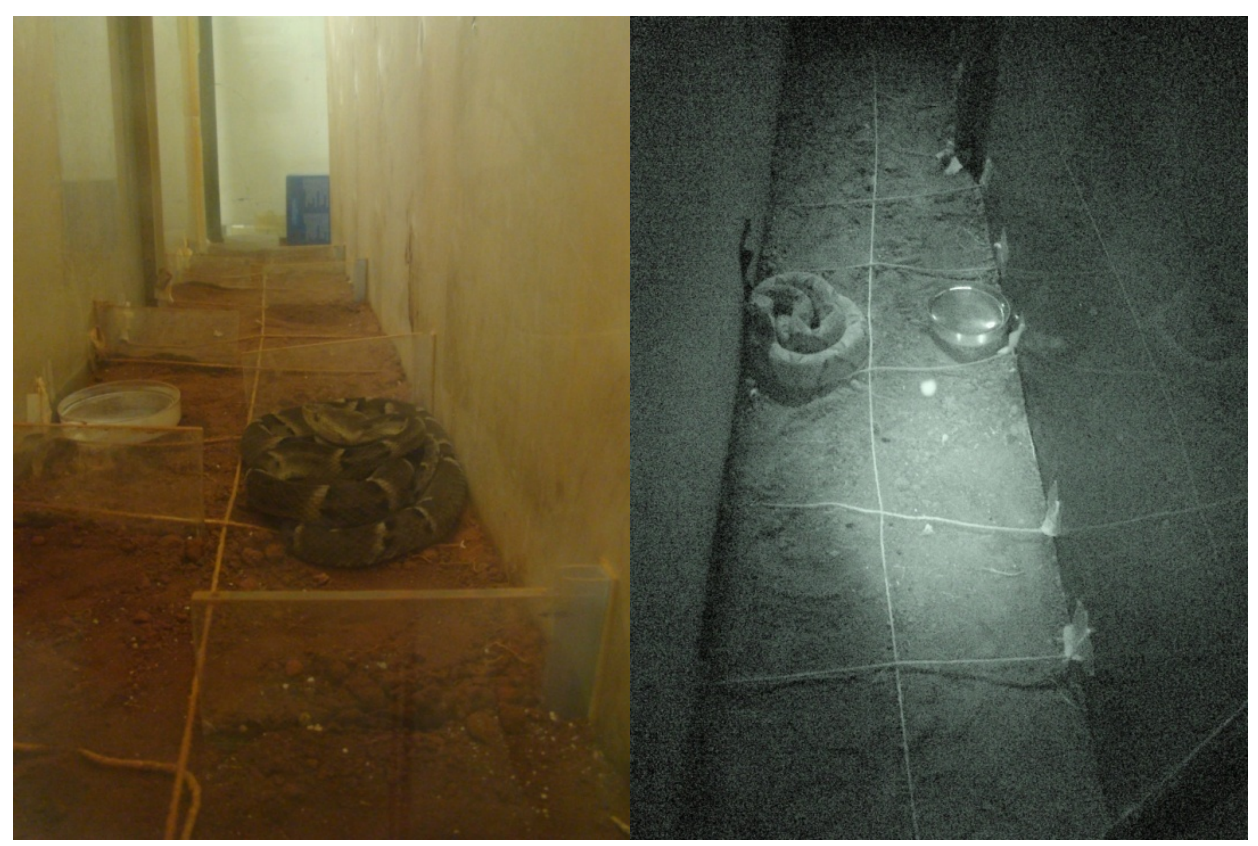

Tabela 4.3.1: Grupos alimentares

\begin{tabular}{|l|l|l|l|}
\hline Grupo & $(\mathrm{n})$ & Peso(g) media \pm SD & $\%$ de alimento \\
\hline A & 10 & $165 \pm 44,6$ & $40 \% \pm 2$ \\
\hline B & 9 & $168,2 \pm 22,2$ & $20 \% \pm 1,8$ \\
\hline C & 10 & $178 \pm 30,8$ & $10 \% \pm 2$ \\
\hline
\end{tabular}




\section{4) Resultados:}

O padrão de movimentação foi predominantemente noturno e 97,36\% de toda a movimentação ocorreram durante a escotofase. Dentro deste período, existiu um marcante pico de movimentação $(56,34 \%)$ no primeiro terço da escotofase, entre 18:00 e 21:00 horas. Um padrão decrescente foi registrado desde então, até que a movimentação cessou durante o início da fotofase (Fig.4.4.1). Após os 30 dias da inversão do fotoperíodo as serpentes retomaram o padrão de atividade e deslocamento na escotofase ( $p>0,05)$ (Fig.4.4.2).

O tempo despendido em deslocamento nos animais jejunos, durante o período de atividade, variou entre 0 e $65.5 \%$, sendo que a média foi de $18,12 \%$. Apesar dos machos terem se movimentado menos $(14,3 \%)$ que as fêmeas $(20,05 \%)$, não houve diferença significativa entre os sexos $(p=0,056)$. Tampouco houve diferença entre os animais na arena com anteparos e na arena sem anteparos $(\mathrm{p}>0,05)$.

No tocante à condição pós-prandial, os grupo A e B, tiveram uma diminuição significativa na taxa de movimentação durante os dias 1,2 e 3 no caso do grupo A e durante os dias 2 e 3 no caso do grupo B se comparados às taxas de movimentação durante o jejum $(p<0,05)$. Os animais do grupo $C$ não mostraram diferença significante $(p>0,05)$ com relação aos animais jejunos (tab.4.4.1). 
Figura 4.4.1: Período de deslocamento das serpentes jejunas. Note o padrão monofásico com um pico de movimentação durante as primeiras três horas da escotofase (as luzes foram apagas as 18h00min horas).

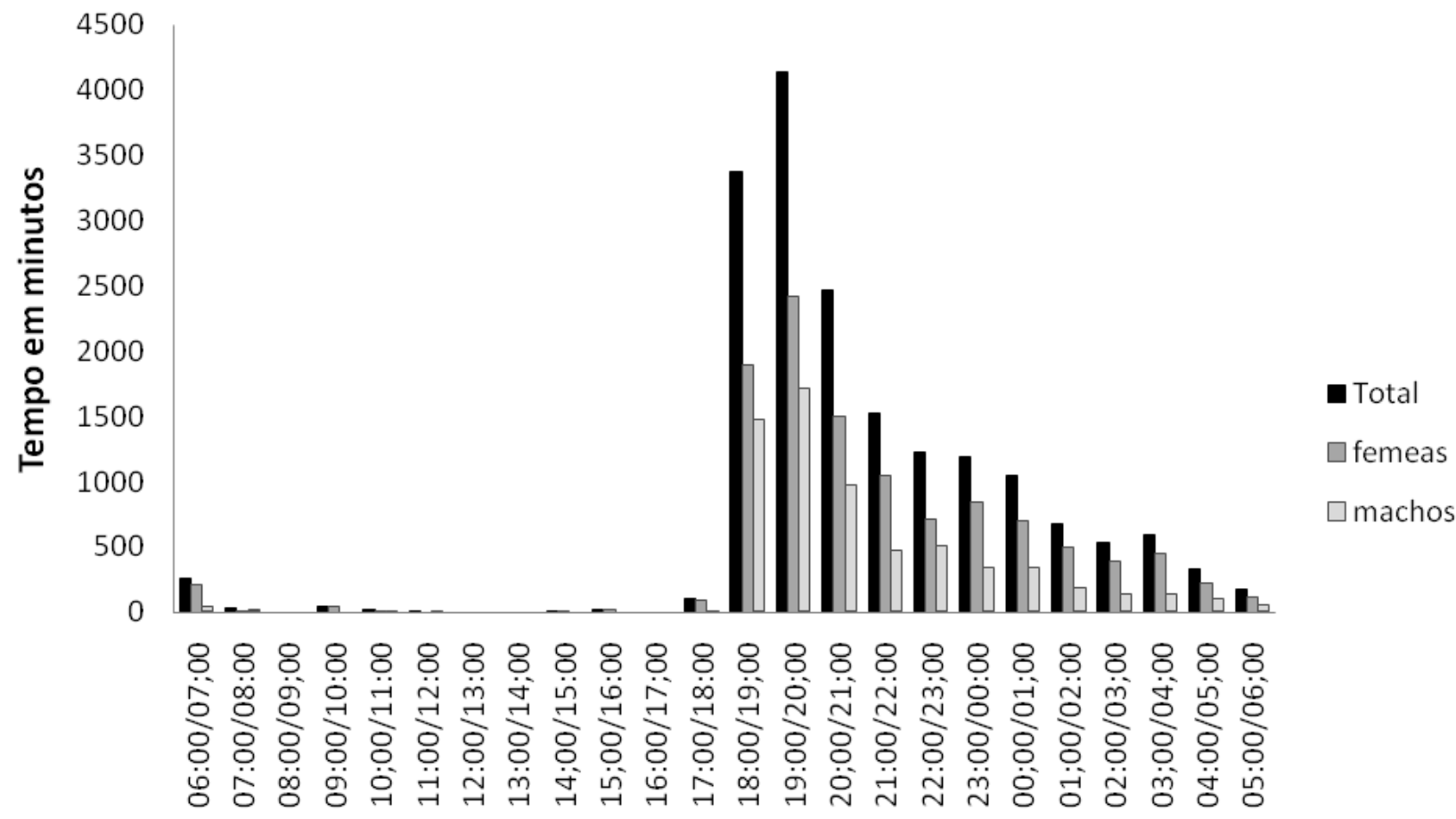

Horário do dia 
Figura 4.4.2: Deslocamento durante os fotoperíodos 12:12 claro/escuro e escuro/claro após ambientação de 30 dias. A barra branca representa a fotofase e a barra negra representa a escotofase.

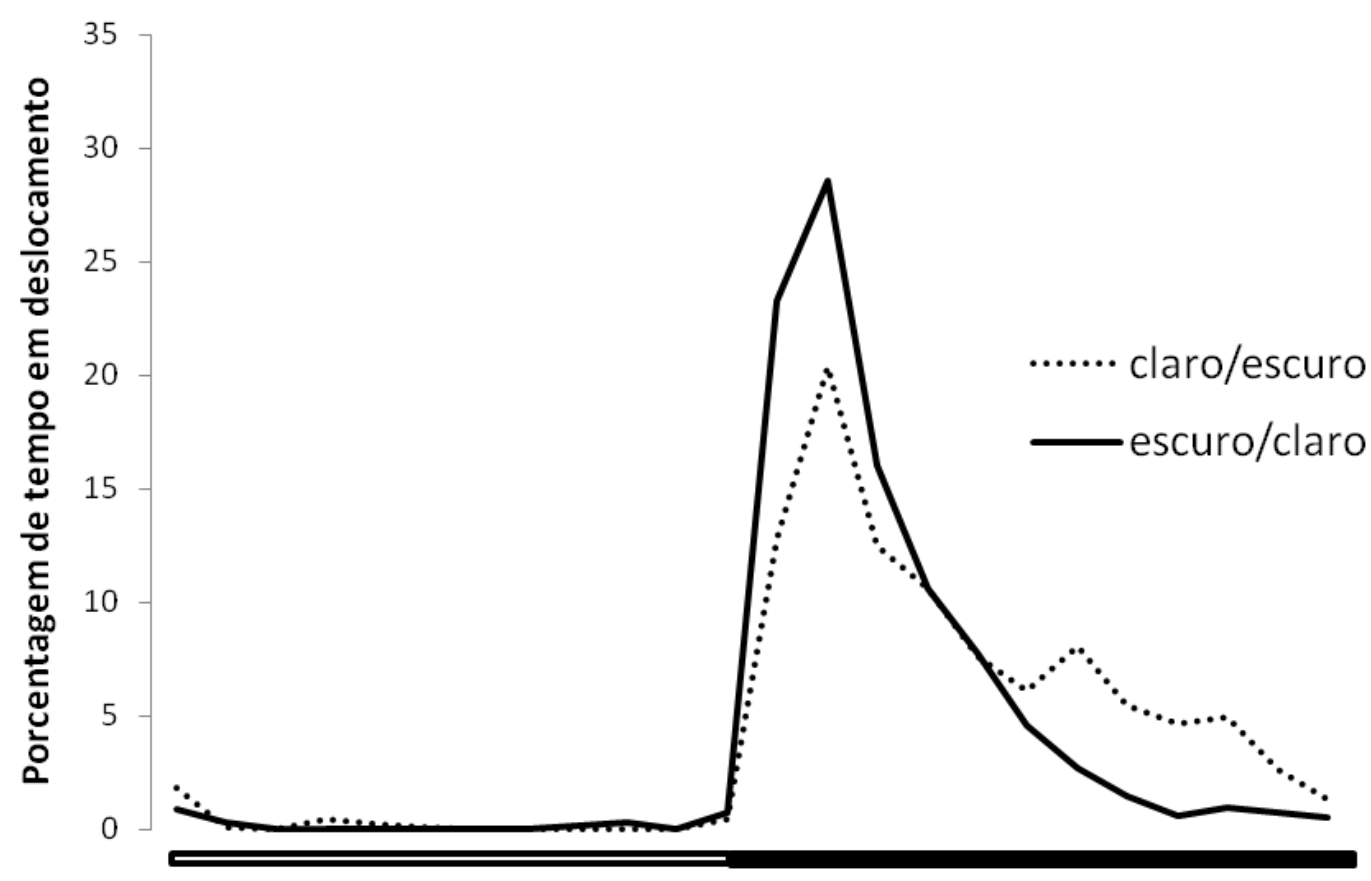

Tabela 4.4.1: Porcentagem de tempo em deslocamento no jejum e nos diversos grupos alimentares. As marcações em negrito representam as diferenças estatisticamente significantes $(p<0,05)$ entre os grupos alimentares e o jejum.

\begin{tabular}{|l|l|l|l|l|l|}
\hline & Noite & Noite 2 & Noite 3 & Noite 4 & Noite 5 \\
\hline Jejum $(\mathrm{n}=122)$ & $18,12 \%$ & $18,12 \%$ & $18,12 \%$ & $18,12 \%$ & $18,12 \%$ \\
\hline Goup A 40\% & $\mathbf{5 , 3 5 \%}(\mathrm{n}=10)$ & $\mathbf{4 , 3 3 \%}(\mathrm{n}=9)$ & $\mathbf{2 , 4 5 \%}(\mathrm{n}=10)$ & $6,65 \%(\mathrm{n}=10)$ & $8,6 \%(\mathrm{n}=10)$ \\
\hline Group B 20\% & $5,5 \%(\mathrm{n}=8)$ & $\mathbf{0 , 7 1 \%}(\mathrm{n}=7)$ & $\mathbf{2 , 5 5 \%}(\mathrm{n}=9)$ & $9,44 \%(\mathrm{n}=9)$ & $6,18 \%(\mathrm{n}=8)$ \\
\hline Group C 10\% & $16,6 \%(\mathrm{n}=10)$ & $21,25 \%(\mathrm{n}=10)$ & $18,5 \%(\mathrm{n}=10)$ & $24,75 \%(\mathrm{n}=10)$ & $26,5 \%(\mathrm{n}=10)$ \\
\hline
\end{tabular}




\section{5) Discussão:}

Nogueira et al (2003), com dados obtidos em campo, mencionam Bothrops moojeni como sendo uma serpente de atividade essencialmente noturna, assim como as demais espécies do gênero, para as quais os dados estão disponíveis (Sazima, 1992; Oliveira \& Martins, 2001; Martins et al, 2002; Campbell \& Lamar, 2004; da Cruz, 2007). O resultado obtido no presente trabalho, com as serpentes em cativeiro, corrobora este padrão noturno. O pico de atividade encontrado no trabalho é concordante com os dados de campo encontrados para Bothrops atrox, que também mostrou o pico de atividade na primeira metade da noite (Oliveira \& Martins, 2001). A sobreposição dos picos de atividade dos animais ao de suas presas é uma característica comum em muitas espécies de serpentes (Downes \& Shine, 1998; Mori et al 2002), sobretudo em espécies que não tem o hábito do forrageamento ativo (Toft, 1985; Luiselli \& Agrimi, 1991; Creer et al 2002,). Apesar de Bothrops moojeni apresentar uma dieta generalista a contribuição dos vários itens alimentares varia ontogenéticamente (Martins \& Gordo, 1993; Martins \& Oliveira, 1999; Martins et al, 2002) e intersexualmente (Nogueira et al, 2003). Assim, a variabilidade da dieta em Bothrops moojeni poderia influenciar nos horários de atividade destes animais, já que presas diferentes podem potencialmente apresentar horários de atividades distintos (Reinert, 1993; Hartmann et al, 2003). Nosso trabalho não detectou nenhuma diferença significativa na atividade entre os indivíduos, o que provavelmente reflete a homogeneidade do tamanho dos animais utilizados no experimento independentemente do sexo. A inexistência de diferença significativa nos itens alimentares para machos e fêmeas de um mesmo tamanho 
(Nogueira et al, 2003) suporta a teoria de que animais de mesmo tamanho potencialmente apresentam horários de deslocamento que se sobrepõe, independentemente do sexo.

A influência da pressão de predação sobre o período de atividade é muito grande para determinadas espécies (Oliveira \& Santori, 1999; Oliveira \& Martins, 2001) fato que pode refletir até mesmo na composição da herpetofauna, bastante conspícuas para os diferentes períodos (Shine, 1979). A pressão de predação como fator determinante, tanto nas taxas de deslocamento quanto no período de atividade, em Bothrops moojeni, poderia refletir em parcas taxas de deslocamento na natureza e taxas mais altas em cativeiro, onde o risco de predação é zero. Ainda assim, os resultados demonstraram que tanto o período, como as taxas de deslocamento, acompanham os dados prévios sobre a ecologia do animal. A variação do período de atividade, supostamente atrelada a um alto custo predatório, já foi vista para pithonídeos (Slip \& Shine, 1988), onde se observam mudanças ontogenéticas, não só no período de atividade, mas também no próprio padrão de cores dos animais.

A influência do sexo (Daltry et al, 1998, Shine et al , 2003) e do estado reprodutivo (Webb \& Shine, 2006) são outros fatores importantes no deslocamento das serpentes, aumentando consideravelmente nos machos de determinadas espécies durante a estação de acasalamento. O tamanho de maturação sexual das serpentes, portanto é outro fator que poderia influenciar bastante a taxa de deslocamento durante determinadas épocas do ano. Em nosso trabalho os machos utilizados tinham o porte de indivíduos sexualmente maduros. Por outro lado, a minoria das fêmeas estudadas tinha o tamanho mínimo necessário para a reprodução (Oliveira, comunicação pessoal). Apesar desta característica do grupo estudado, não foi detectada diferença significativa entre o deslocamento entre os 
sexos. Este dado poderia sugerir a ausência do aumento de atividade por parte dos machos reprodutivos ou um artefato da condição de cativeiro.

A influência de fatores abióticos no período de atividade foi relatada em trabalhos prévios com viperídeos e parece haver uma elevada relação entre a temperatura e o período de atividade, principalmente para animais de clima temperado e subtropical (Heatwole, 1976). Para animais de zonas tropicais parece haver uma grande influência de fatores ligados à umidade relativa e período de chuvas (Daltry et al, 1998; Sun et al, 2000). Outros fatores abióticos como, o ciclo lunar, também tiveram sua influência constatada no deslocamento de determinados animais (Madsen \& Osterkamp, 1982; Clarke et al, 1996; Houston \& Shine, 1994). Os resultados da inversão do fotoperíodo em B. moojeni foram similares aos obtidos com B. jararacussu (da Cruz, 2007), demonstrando que após a inversão do fotoperíodo as serpentes retomam seu ciclo atividade (movimentação na escotofase) após um período de ambientação de 30 dias.

O deslocamento pós-alimentar muito provavelmente tem função distinta do pré-alimentar e apesar do estado alimentar não ter influenciado no período em que ocorreu a atividade, a quantidade de alimento ingerido influenciou na freqüência do deslocamento. A redução da movimentação das serpentes que ingeriram maiores quantidades de alimento gera ao menos duas hipóteses não mutuamente excludentes: os animais deixariam de se deslocar por já estarem suficientemente alimentados, ou animais que comeram grandes proporções alimentares teriam um custo de deslocamento muito alto, devido ao aumento da massa e ao risco de predação. A manutenção das taxas de deslocamento dos animais do grupo C, com relação às taxas durante o jejum pode significar continuidade na procura de bons locais para a alimentação, ou pode representar movimentos termorregulatórios pós-prandias, já que a 
termofilia pós-prandial já foi detectada em muitas serpentes (Lysenko \& Gillis, 1980; Naulleau, 1983; Lillywhite, 1987; Sievert \& Andreadis, 1999, Sievert et al 2005).

Contraditoriamente, os animais que ingeriram a maior quantidade de alimento (grupos A e B) não apresentaram um aumento em suas taxas de deslocamento, o que pode sugerir que a utilização do calor gerado durante a digestão poderia dispensar a necessidade de um deslocamento termorregulatório, uma vez que tanto a termogênese pós-prandial quanto o custo termorregulatório são maiores para animais que se alimentaram de grandes proporções alimentares (Tattersall et al, 2004).

As questões relacionadas ao deslocamento dos animais são complexas e múltiplas, o que torna difícil qualquer aproximação mais precisa através de estudos pontuais. Os períodos e taxas de atividade nos revelam uma intrínseca trama de influências de inúmeros fatores ecológicos e fisiológicos. Estudos futuros que acessem, tanto na natureza como em cativeiro, a influência dos fatores abióticos e fisiológicos no deslocamento e nos horários de atividade são fundamentais para a compreensão mais exata dos motivos e dos padrões de deslocamento nas diversas espécies de serpentes. 
Bibliografia:

Angelici, F. M.; Effah, C.; Akpaninyang, M.; Luiselli, L. (2000). A preliminary radiotracking study of movements, activity patterns and habitat use of freeranging gaboon vipers, Bitis gabonica, Revue d'Ecologie: La Terre et la Vie 55:45-55.

Bonnet, X.; Naulleau G.; Shine, R. (1999). The dangers of leaving home: dispersal and mortality in snakes, Biological Conservation 89:39-50.

Branch, W. R.; Bauer, A. M.; Lamb, T. (2002). Bitis caudalis (horned adder), Prey size, Herpetological Review 33, 137-138.

Campbell, J. A. \& Lamar, W. W. (2004). In Venomous of the western hemisphere, vol 1, Cornell Univers, Press, Ithaca, New York.

Clarke, J. A.; Chopko, J. T. \& Mackessy, S. P. (1996). The effect of moonlight on activity patterns of adult and juvenile praire rattlesnakes (Crotalus viridis viridis), $J$. Herpetol. 30: 192-197.

Creer, S.; Chou, W.; Malhotra, A.; Thorpe, R. S. (2002). Offshore Insular variation in the diet of the Taiwanese bamboo viper Trimeresurus stejnegeri (Schimidt), Zoological science 19: 907-913.

Cundall, D.; Greene.; H.W. (2000). Feeding in snakes, Feeding, Form, Function and Evolution in Tetrapod Vertebrates (ed, K,E, Schwenk), pp, 293-333, Academic Press, San Diego.

Da Cruz, J. G. P. (2007). Ritmo circadiano e atividade locomotora em Bothrops jararacussu (Serpentes: Viperidae). Biotemas 20, vol 3, 55-61. 
Daltry, J. C.; Ross, T.; Thorpe, R. S.; Wuster, W. (1998). Evidence that humidity influences snake activity patterns: a field study of the Malayan pit viper Calloselasma rhodostoma, Ecography 21: 25-34.

Downes, S. \& Shine, R. (1998). Sedentary snakes and gullible geckos: predator-prey coevolution in nocturnal rock-dwelling reptiles. Anim. Behav., 55, 1373- 1385.

Egler, S. G.; Oliveira, M. E.; Martins, M. (1996). Bothrops atrox (Common Lancehead), Foraging behavior and ophiophagy, Herpetol. Rev., 27:22-23.

Gibbons, J. W. \&, Semlitsch, R. D. (1987). Activity patterns, In: R,A, Seigel, J,T, Collins, and S,S, Novak (eds,), Snakes: Ecology and Evolutionary Biology, pp, 396-421, MacMillan Publishing Company, New York.

Greene, H. W. (1997) In Snakes: The Evolution of Mystery in Nature, Univers, Californ, Press, London.

Gregory, P. T.; Macartney, J. M.; Larsen, K. W. (1987). Spatial patterns and movements. - In: Seigel, R. A., Collins, J. T. and Novak, S. S. (eds), Snakes: ecology and evolutionary biology. Macmillan, pp. 366-395.

Hartmann, P. A,; Hartmann M. T.; Giasson, L. O. M. (2003). Uso do habitat e alimentação em juvenis de Bothrops jararaca (Serpentes: Viperidae) na mata atlântica do sudeste do Brasil, Phyllomedusa 2 (1), PP 35-41.

Heatwole, H. (1976). Reptile Ecology, Univ, of Queensland, Press in St, Lucia, Queensland.

Houston, D. and Shine, R. (1994). Movements and activity patterns of arafura filesnkes (Serpentes: Acrochordidae) in Tropical Australia, Herpetologica 50: 349-357, 
Larsen, K. (1987). Movements and behavior of migratorygarter snakes, Thamnophis sirtalis, Canadian Journal of Zoology 65:2241-2247.

Lillywhite, H. B. (1987). Temperature, energetics, and physiological ecology, In snakes: Ecology and Evolutionary Biology, (Edited by Seigel R, A,; Collins J, T, And Novak S, S,), pp 422-477, Macmillan, New York.

Lysenko, S. \& Gillis, J. E. (1980). The effect of ingestive status on thermorregulatory behavior of Thamnophis sirtalis sirtalis and Thamnophis sirtalis parietalis, J, Herpetol, 14, $155-159$.

Luiselii, L.; Agrimi, U. (1991). Composition and variation of diet of Vipera aspis francisciredi in relation to age and reproductive stage, Amphibia 12: 137-144.

Macartney, J. M.; Gregory, P. T.; Larsen, K. W. (1988). A tabular survey of data on movements and home ranges of snakes. - J. Herpetol. 22: 61-73.

Madsen, T.; Osterkamp, M. (1982). Notes on the biology of the fish-eating snake Lycodonomorphus bicolor in lake Tanganyika, J. Herpetology 16: 185-188.

Martins, M.; Gordo M. (1993). Bothrops atrox (Common Lancehead), Diet, Herpetol. Rev. 24:151-152,

Martins, M.; Oliveira, M. E. (1999). Natural history of snakes in forests of the Manaus Region, Central Amazonia, Brazil, Herpetol. Nat. Hist. 6:78-150.

Martins, M.; Marques, O. A. V.; Sazima, I. (2002). Ecological and phylogenetic correlates of feeding habits in Neotropical pitvipers (genus Bothrops), In Schuett G, W,; Hoggren M,; Douglas M, E, And Greene H, W, In Biology of the Vipers, pp 307-328, Eagle Mountain Publishing, Eagle Mountain, UT. 


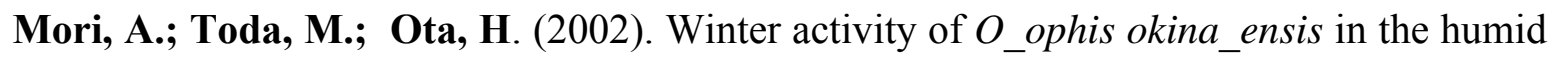
subtropics: foraging on breeding frogs under cool temperature. - In: Hoggren, M. (ed.), Biology of the vipers. Uppsal Peterson, C. R.

Naulleau, G. (1983). The effects of temperature on digestion in Vipera aspis, J, Herpetol, $16,166-177$

Nogueira, C.; Sawaya, R. J.; Martins, M. (2003). Ecology of the pitviper, Bothrops moojeni, in the Brazilian cerrado, J, Herpetol, vol 37, n4, pp 653-659.

Oliveira, M. E.; Santori, R. T. (1999). Predatory behavior of Opossum Didelphis albiventris on the Pitviper Bothrops jararaca, Studies on Neotropical Fauna and Environment 34: 72-75.

Oliveira, M. E.; Martins, M. (2001). When and where to find a pitviper: activity patterns and habitat use of the lancehead Bothrops atrox in central Amazonia, Brazil, Herpetological Natural History 8: 101-110.

Reinert, H. K. (1992). Radiotelemetric field studies of pitvipers: data acquisition and analysis, In Biology of Pitvipers, Selva, pp 185-198.

Reinert, H. K. (1993). Habitat selection in snakes, in Snakes ecology and behavior, New York, McGraw-Hill, pp 201-240.

Sazima, I. (1989). Comportamento alimentar da jararaca, Bothrops jararaca: encontros provocados na natureza, Ciência e Cultura 41, 500-505.

Sazima, I. (1991). Caudal luring in two Neotropical pitvipers Bothrops jararaca and Bothrops jararacussu, Copeia 1991, pp 245-248.

Sazima, I. (1992). Natural history of jararaca pit viper, Bothrops jararaca in southeastern Brazil, Biology of the Pitvipers, tyler (Texas) pp 199-216. 
Secor, S. M. (1994). Ecological significance of movements and activity range for the sidewinder, Crotalus cerastes. Copeia 1994, 631-645.

Shetty, S. \& Shine, R. (2002). Activity patterns of yellow lipped sea kraits (Laticauda colubrina) on a Fijian island, Copeia 2002:77-85.

Shine, R. (1979). Activity pattern in Australian elapid snake (squamata:Serpente:Elapidae), Herpetologica, vol 35, pp 1-11.

Shine, R. \& Lambeck, R. (1985). A radiothelemetric study of movements, thermorregulation and habitat utilization of Arafura filesnake (Serpentes: Acrochordidae), Herpetologica, 41: 351 .

Shine, R. (1987). Intraespecific variation in thermoregulation, movements and habitat use by Australian blacksnake Pseudechis porphyriacus (Elapidae), J. Herpetology 21, 165-177.

Shine, R. \& Fitzgerald, M. (1996). Large snakes in a mosaic rural landscape: the ecology of carpet pythons Morelia spilota (Serpentes:Pythonidae) in coastal eastern Australia Bio. Conserv. 76, 113-122,

Shine, R.; Sun, L.; Fitzgerald, M.; Kearney, M. (2003). A radiotelemetric study of movements and thermal biology of insular Chinese pit-vipers (Gloydius shedaoensis, Viperidae), Oikos 100, 342-352.

Shine, R.; Bonnet, X.; Elphic, M. J.; Barrott, E. G. (2004). A novel foraging mode in snakes: browsing by the sea snake Emydocephalus annulatus (Serpentes: Hidrophiidae) Functional ecology 18, pp 16-24.

Sievert, L. M. \& Andreadis (1999). P, Specific dynamic action and postprandial thermophily in juvenile northern water snakes, Nerodia sipedon, J, Thermal biology, vol $24,51-55$. 
Sievert L, M.; Jones, D. M.; Puckett, M. W. (2005). Postprandial thermophily, transit rate and digestive efficiency of juvenile cornsnake, Pantherophis guttatus, J, Thermal biology, vol 30, pp 354-359.

Slip, D. J.; Shine, R. (1988). Habitat use, movements and activity patterns of free-ranging diamond pythons, Morelia spilota spilota (Serpentes:Boiidae): a radiotelemetric study, Aust. Wildl. Res. 15, 515-531.

Sun, L.; Shine, R.; Zhao, D.; Tang, Z. (2000). Biotic and abiotic influences on activity patterns of insular pit-vipers (Gloydius shedaoensis, Viperidae) from north-eastern China. Biol. Conserv. 97: 387-398.

Tattersall, G. J.; Milson, W. K.; Abe, A. S.; Brito S. P.; Andrade, D. V. (2004). The thermogenesis of digestion in rattlesnakes, J. Exp. Biol., vol, 207, pp 579-585,

Toft, C. A. (1985) Resource parttioning in amphibians and reptiles, Copeia 1985 1-21.

Toledo, L. F.; Abe, A. S. \& Andrade D. V. (2003). Temperature and meal size effects on the postprandial metabolism and energetics in a Boid snake. Physiological and Biochemical Zoology, 76(2):240-246.

Vanzolini, P. E. (1948). Notas sobre ofídeos e lagartos da cachoeira de Emas, no município de Pirassununga, Estado de São Paulo, Revista Brasileira de Biologia, v,8, 377400.

Webb, J. K.; Shine, R. (2006). A field study of spatial ecology and movements of threatened snake species, Hoplocephalus bungaroides. Biol. Conserv., 82: 203-217.

Whitaker, P. B.; Shine, R. (2003). a radiotelemetric study of movements and shelter-site selection by free-ranging brown snakes (Pseudonaja textilis, Elapidae) Herpetological monographs 17, 130-144. 


\section{Capítulo 5: Termogênese pós-prandial em Bothrops moojeni (Serpentes:}

\section{Viperidae)}

Stuginski, D. R. ${ }^{1}$; Tattersall, G. J. ${ }^{2}$; Abe, A. S. ${ }^{3}$; Fernandes, W. ${ }^{4}$

Departamento de Fisiologia do IB-USP ${ }^{1}$, Department of Biological Science Brock Universisty Canada $^{2}$, Departamento de Zoologia da Unesp-RC ${ }^{3}$, Laboratório de Herpetologia do Instituto Butantan ${ }^{4}$

\subsection{1) Abstract:}

Snakes were for long considered incapable to generate heat fueled by aerobic metabolism, except for brooding pythons. However, recent studies proved that some species are able to elevate their body temperature without muscle contraction or external heat source. Such thermogenic capacity is supported by high metabolic rate that follows digestion and assimilation of food (specific dynamic action - SDA). Snakes have a low maintenance cost and most species can stand for long fasting time, particularly after ingesting a great meal. The energy produced during digestion of such meal can generate significant increase in body temperature. The present study investigated thermogenic response after feeding in the Brazilian lancehead, Bothrops moojeni, using thermal images taken in temperature controlled environment at $30^{\circ} \mathrm{C}$. The 12 snakes were divided into two groups and followed for 72 hours after fed a meal representing $10-20 \%$ and $30-40 \%$ of their body weight, 
respectively. The results showed thermogenic digestive response with an increase up to 1.6 ${ }^{\circ} \mathrm{C}$ of skin temperature. Thermal heat production peak occurred between 33 to 36 hours after feeding in both groups, and the duration of thermogeny varied with the meal size. The result showed high correlation between thermogenic data and SDA in snakes. The significant increase of body temperature after feeding and its maintenance for extended time suggest a physiological advantage to keep high metabolic rate despite of environmental temperature.

Key words: thermogenesis, vipers, Bothrops, digestion, specific dynamic action

\subsection{2) Resumo:}

As serpentes foram consideradas por muito tempo como incapazes de gerar calor através de seu metabolismo aeróbico, à exceção das pythons no choco. Entretanto, estudos recentes mostraram que algumas espécies são capazes de aumentar a temperatura corporal sem recorrer a fontes externas de calor ou contrações musculares. Esta termogênese ocorre devido aos enormes níveis metabólicos atingidos durante a digestão (specific dynamic action - SDA). Em geral as serpentes têm um baixo custo energético de manutenção e a maioria das espécies é capaz de permanecer longo período em jejum e depois se alimentar de uma grande ingesta. A energia produzida durante a digestão destas grandes refeições pode gerar um significativo aumento na temperatura corpórea dos animais. O presente estudo investigou a termogênese pós-prandial em Bothrops moojeni, através de imagens térmicas tomadas em um ambiente termoestável a $30^{\circ} \mathrm{C}$. As 12 serpentes foram divididas em 2 grupos e acompanhadas pelas 72 horas após ingerirem refeições equivalentes a 10- 
$20 \%$ e $30-40 \%$ de seu próprio peso, respectivamente. Os resultados mostraram que a resposta termogênica pós-prandial levou a um aumento de $1,6^{\circ} \mathrm{C}$ da temperatura da pele das serpentes. O pico térmico ocorreu entre 33 e 36 horas após a alimentação em ambos os grupos e a duração da termogênese variou conforme o tamanho da ingesta. Os resultados mostraram uma alta correlação entre a termogênese pós-prandial e a SDA das serpentes. O aumento significativo da temperatura corporal e a sua manutenção por certo tempo sugerem que estes animais são capazes de manter altas taxas metabólica durante a digestão independente da temperatura do ambiente.

\section{2) Introdução:}

As serpentes representam um dos mais bem sucedidos grupos de Squamata e são representadas por cerca de 18 famílias e 2700 espécies encontradas em praticamente todas as partes da Terra, excetuando latitudes extremas (Greene, 1997). Um dos motivos para o grande sucesso das serpentes é sua demanda energética extremamente baixa (Chappell \& Ellis, 1987). Este baixo custo energético as possibilita viver com poucas refeições durante o ano, além disso, são capazes de ingerir presas de proporções enormes, algumas maiores até do que a própria serpente (Greene, 1997). Para comportar um processo digestório tão grande as serpentes sofreram uma série de mudanças tanto morfológicas como fisiológicas em seu trato gastrointestinal: modulações do tamanho das vilosidades intestinais e do volume hepático, mudanças no equilíbrio ácido base, pressão sanguínea e ventilação pulmonar, "shunts" cardíacos, com isso, aumentando o seu consumo de O2 (Lignot et al 
2005; Ott \& Seccor, 2006; Overgaard \& Wang, 2002; Secor, 2005; Starck \& Beese, 2002; Wang, 2003). O aumento do consumo de O2 é bastante interessante do ponto de vista da dinâmica metabólica, já que após a ingestão de grandes porcentagens de alimento, já foram descritos aumentos da ordem de 18 vezes o consumo basal, portanto, muitas vezes superior àquele observado durante atividades físicas como a locomoção (Andrade et al, 1997; Secor \& Diamond, 1997b; Secor \& Boehm, 2006; Toledo et al, 2002). Este aumento metabólico durante o processo de digestão e absorção alimentar é chamado de "specific dynamic action" (SDA) e já foi descrito para diversos vertebrados, porém, sua exacerbada amplitude registrada nas serpentes, chama a atenção quanto à implicação desta resposta metabólica (e.g. Grayson et al, 2005; Mzilikazi N. \& Lovegrove, 2006; Secor et al, 2007).

Por muito tempo acreditou-se que os ectotérmicos em geral operavam a temperaturas fixas, mas atualmente assume-se que operem em faixas térmicas, já que diferentes processos fisiológicos, como a digestão, possuem temperaturas ótimas variáveis (Bustard, 1967; Lang 1979, Pough, 1983; Huey, 1982; Huey \& Hertz, 1984). Para solucionar os problemas da ectotermia, relacionada à digestão, muitas serpentes apresentam resposta termofílica pós-prandial, aquecendo o corpo ou ao menos porções específicas do corpo para maximizar o processo digestório (Regal, 1966; Mcginnis \& Moore, 1969; Lysenko \& Gillis, 1980; Huey, 1982; Lillywhite, 1987). As respostas termofílicas podem ser de difícil detecção ou não ocorre em alguns animais (Peterson et al, 1993; Tu \& Hutchinson, 1995). O simples aumento da temperatura por si só não garante ao animal um melhor balanço energético durante a digestão. A otimização digestória ocorre quando os animais atingem uma temperatura que maximize seu processo digestório, digerindo a refeição o quanto antes e gastando o mínimo de energia por unidade absorvida, resultando assim em um maior 
“lucro" energético final (Grenwald \& Kanter, 1979; Naulleau 1983) . No entanto, nem sempre as serpentes são capazes de se deslocarem até um local aquecido durante a digestão, pois a ingestão de presas grandes pode limitar bastante a movimentação, aumentando significantemente o risco de predação e o custo energético associado, podendo restringir a resposta termofílica (Huey \& Slatkin 1976). O hábito noturno também pode reduzir a possibilidade de encontrar microambientes para termorregulação, bem como alguns ambientes ou estações podem ser limitantes na manutenção de temperaturas adequadas à digestão (Shine \& Lambeck, 1985; Daltry et al, 1998; Mori et al, 2002). Devido a isso, as serpentes muitas vezes recorrem a estratégias fisiológicas e comportamentais para compensar esta limitação, em especial as que se alimentam de grandes presas, através da termogênese pós-prandial (Tattersall et al , 2004).

A termogênese foi bem estudada nos animais endotérmicos, sendo ligada a mecanismos associados a espasmos musculares e outros como a atuação da "uncoupling protein 1" (UCP1) sobre os depósitos de gordura marrom nos tecidos subcutâneos (Fontanillas et al, 2005, Jastroch et al, 2007), aumento metabólico via indução adrenérgica (Mzilikazi \& Lovegrove, 2006), aumento na expressão dos hormônios tireoidianos, aumento da expressão dos hormônios de crescimento e através da SDA (Guyton \& Hall, 2000), já que o principal subproduto do metabolismo aeróbico é o calor.

Nas serpentes a termogênese foi descrita em pythonideos gestantes, que permanecem enrodilhadas ao redor de seus ovos, praticando uma série de pequenas contrações musculares, possibilitando assim a geração de calor e a manutenção da temperatura corpórea e a dos ovos alguns grau acima da ambiental (Hutchinson et al, 1966; Van Mierop \& Barnard, 1978; Harlow \& Crigg, 1984; Shine et al, 1996). Nos últimos anos alguns 
experimentos quantificaram outra espécie de termogênese em serpentes, a geração de calor decorrente de altas taxas metabólicas durante a digestão (SDA), principalmente mediante a ingestão de grandes volumes alimentares (Tattersall et al, 2004). A origem deste processo parece exclusivamente metabólica, ligada aos processos de "upregulation" das vilosidades, produção das enzimas digestivas, produção de proteína (Secor, 2003). Outros fatores, como a composição do alimento parecem ter grande efeito na (SDA) e por conseguinte na termogênese pós-prandial. (Andrade, 1997; McCue et al, 2005; Secor et al, 2007). A possibilidade de gerar uma razoável quantidade de calor, juntamente com a capacidade de retê-la ao máximo através de manobras comportamentais, pode ser importante no processo digestivo destes animais.

O objetivo do presente estudo foi avaliar a termogênese em B. moojeni, associada à elevação do metabolismo pós-prandial e sua relação com o tamanho da presa ingerida.

\section{3) Material e Métodos:}

5.3.1) Animais: Foram utilizados no experimento 12 exemplares de Bothrops moojeni mantidas nas condições supracitadas (Ver Capítulo 2).

\subsection{2) Calibragem das medidas de temperatura corporal: (Ver tópico 3.2.4)}

5.3.3) Captura e análise das imagens térmicas: Os animais passaram por um período de aclimatação térmica de 24 horas antes do início do experimento e as imagens térmicas foram feitas com a câmera de captura de infravermelho MycroScan 7515 Thermal Imager (Mycron Infrared $®$, Oakland, NY, USA), que produz imagens de 12 bits (320x240 pixels) 
com poder de resolução de $0,1^{\circ} \mathrm{C}$. Todas as leituras térmicas foram automaticamente corrigidas para corpos não negros assumindo um índice de emissividade de 0,95, previamente estimado para tecidos vivos (Tattersall et al, 2004). Os animais foram mantidos em gaiolas plásticas com tampas de acrílico (40x 25x 20cm), colocadas em duas estufas de temperatura controlada a $30 \pm 0.2^{\circ} \mathrm{C}$ e as imagens foram tomadas após a abertura da janela frontal de cada gaiola a uma distância de cerca de 30-45 cm da serpente, nas horas $0,6,12,24,27,33,36,48,51,57,60$ e 72 após a alimentação.

As imagens foram analisadas através do software Mikronspec RT, sempre mensurando as temperaturas máxima, mínima e media do corpo do animal, a temperatura do substrato e a temperatura das narinas dos animais. O controle do experimento foi feito com a imagem térmica de cada um dos animais feita no tempo 0 pré-alimentar, sendo que a quantificação da resposta termogênica foi feita através da diferença da temperatura $(\Delta t)$ dos animais dos diferentes grupos entre o tempo pós-alimentar e o tempo 0 pré-alimentar. $\mathrm{O} \Delta \mathrm{t}$ de cada hora foi analisado assim como as diferentes respostas de cada um dos grupos através do software Instat3, sendo realizado o teste de comparação de Dunnet para as diferentes horas dentro do mesmo grupo e o teste T não pareado com correção de Welch para comparar os diferentes grupos dentro da mesma hora. Para todos os testes o nível de significância usado foi de 0,05 .

5.3.4) Grupos alimentares: Foram constituídos dois grupos alimentares de acordo com a proporção de alimento que os animais receberam, o grupo $A(n=6)$ recebeu $10-20 \%$ do próprio peso em alimento (Mus musculus), e o grupo $\mathrm{B}(\mathrm{n}=5)$ recebeu $30-40 \%$, de 
camundongos previamente abatidos (Tab. 5.3.1). Houve ainda um dos animais que não aceitou alimentação no período e foi mantido jejuno durante o experimento (animal C).

Tabela 5.3.1: Grupos alimentares

\begin{tabular}{llll}
\hline Grupos & $(\mathrm{n})$ & Massa da serpente $(\mathrm{g})$ & $\%$ de alimento \\
A & 6 & $142 \pm 14,6$ & $10-20 \%$ \\
B & 5 & $142.2 \pm 14,2$ & $30-40 \%$ \\
\hline
\end{tabular}

\section{4) Resultados:}

Os resultados mostram a resposta termogênica em ambos os grupos alimentares (Fig.5.4.1 a 5.4.4). O Grupo A (10-20\%), apresentou resposta termogênica significativa $(p<0,05)$, entre 12 e 60 horas pós-prandiais, acentuando-se ainda mais após 24 horas $(p<0,01)$. O $\Delta t$ máximo ocorreu durante a $33^{\mathrm{a}}$ hora, atingindo uma média de $0,98^{\circ} \mathrm{C}$, variando entre 0,7 e $1,3^{\circ} \mathrm{C}$. O grupo B (30-40\%), apresentou resposta termogênica altamente significantiva $(\mathrm{p}<0,01)$ a partir de 12 horas até o término do experimento na $72^{\mathrm{a}}$ hora. $\mathrm{O} \Delta \mathrm{t}$ máximo ocorreu durante a $36^{\mathrm{a}}$ hora atingindo uma média de $1,44^{\circ} \mathrm{C}$, variando entre $1,3^{\circ} \mathrm{C}$ até $1,6^{\circ} \mathrm{C}$. Houve diferença significativa entre os grupos desde o início $(p<0,05)$, aumentando ainda 
mais após 33 horas da alimentação $(\mathrm{p}<0.01 \mathrm{a} p=0.0005)$. As diferenças entre $\mathrm{o} \Delta \mathrm{t}$ do grupo A e do grupo B durante os picos térmicos (33 e 36 horas) foram respectivamente de 0,44 e $0,48^{\circ} \mathrm{C}$. A diferença entre o $\Delta \mathrm{t}$ dos grupos durante a $72^{\mathrm{a}}$ hora, quando o grupo A já havia voltado à temperatura basal foi de $0.61^{\circ} \mathrm{C}$.

Figura 5.4.1: Termogênese pós prandial. Significância entre o tempo t e t0 $p<0,05(*)$ e $p<0,010(\$)$

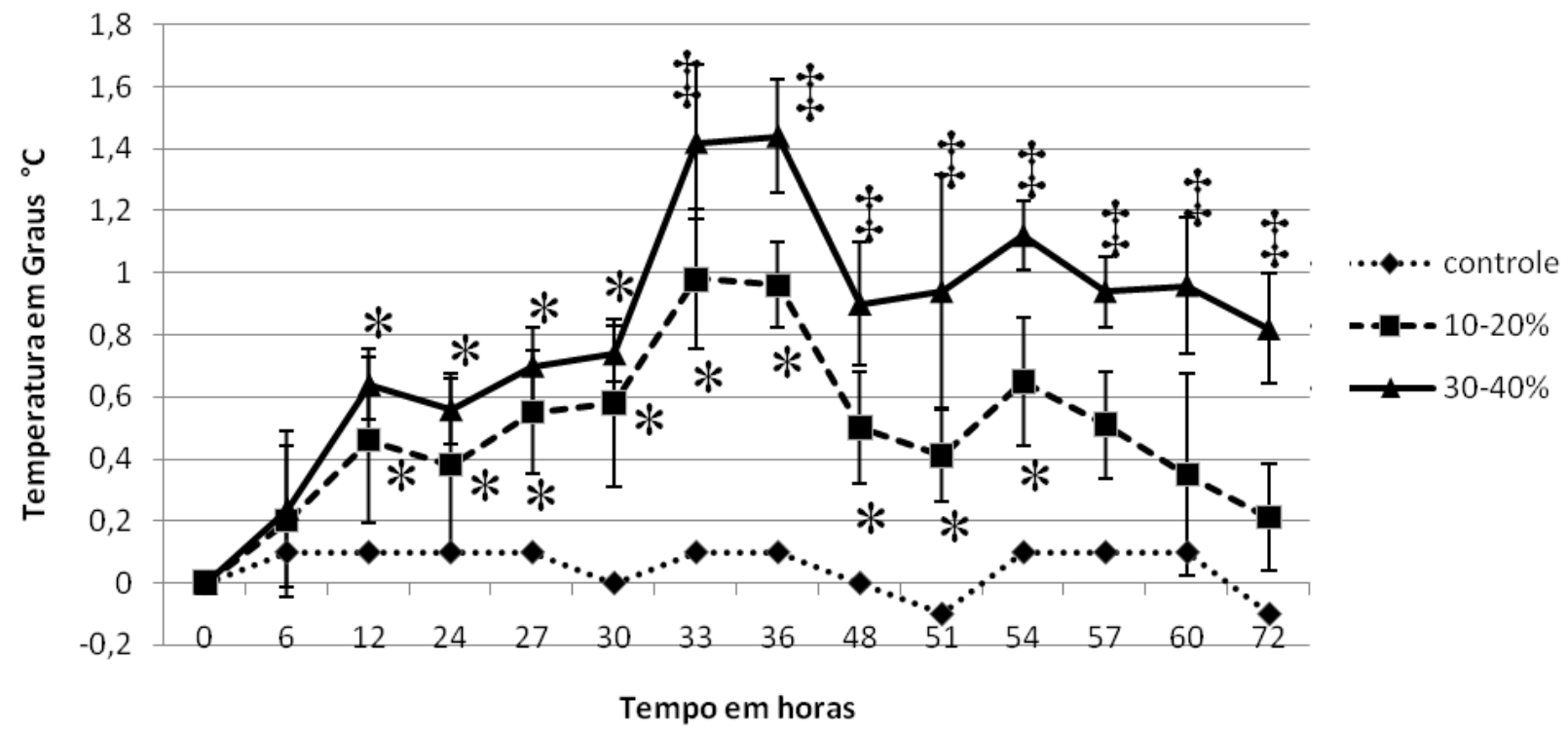


Figura 5.4.2: Imagens térmicas grupo B: 0, 24, 36 e 72 horas pós-prandiais (a,b,c,d).

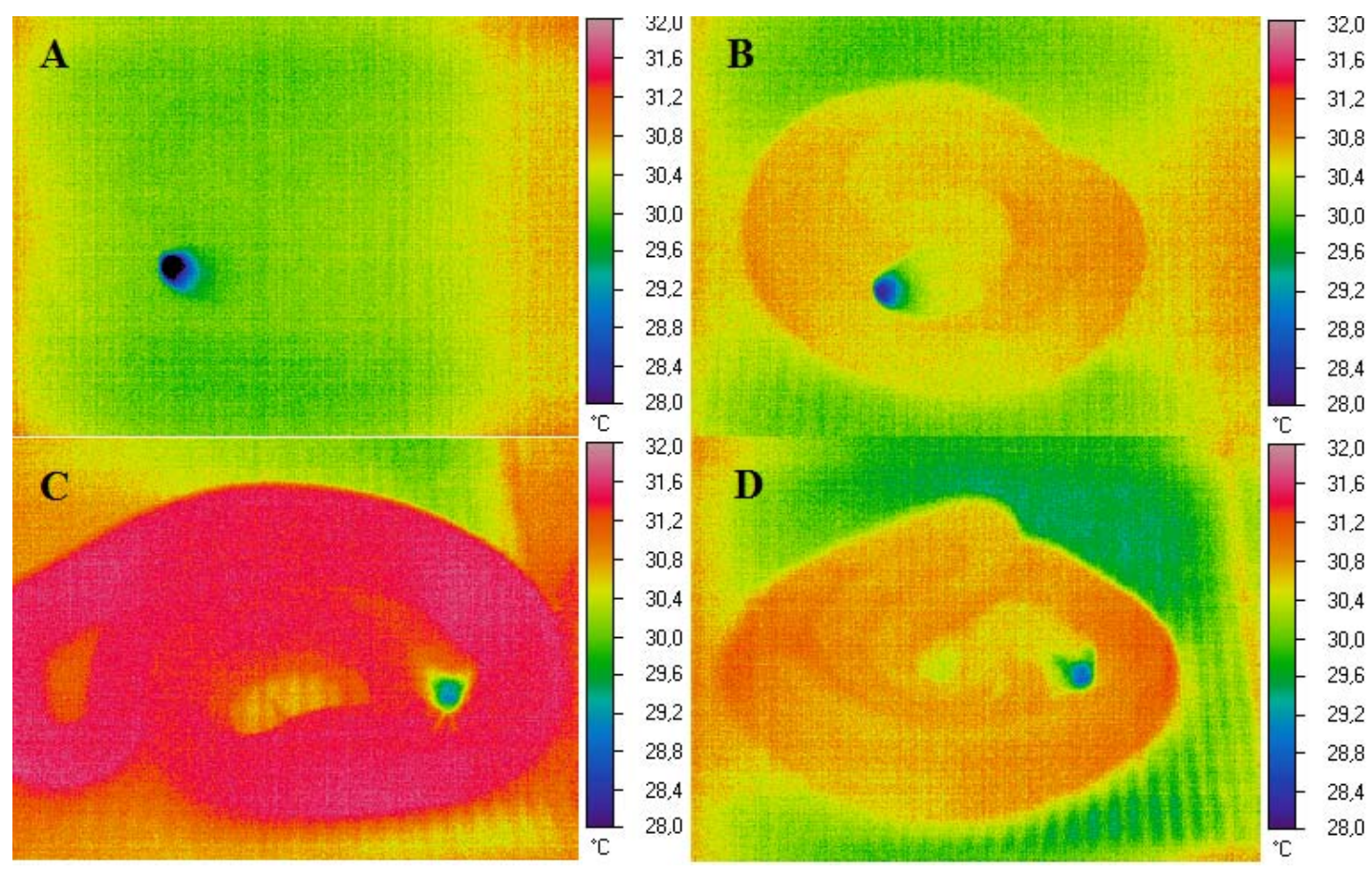

Figura5.4.2: Imagens térmicas Grupo A: 0, 24, 33 e 72 horas pós-prandiais (a,b,c,d).

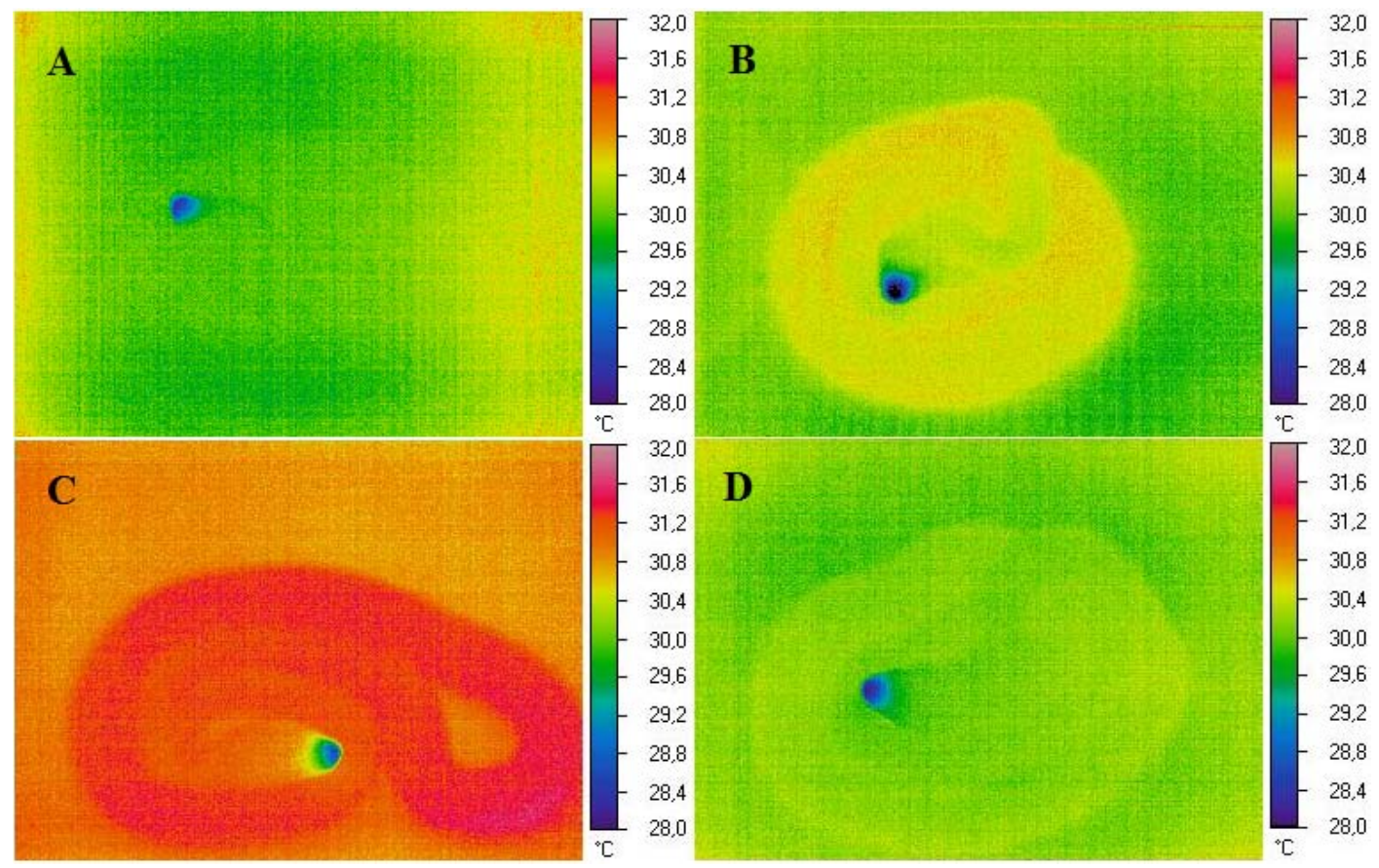


Figura 5.4.4: Animal jejuno 0, 24, 33 e 72 horas (a,b,c,d).

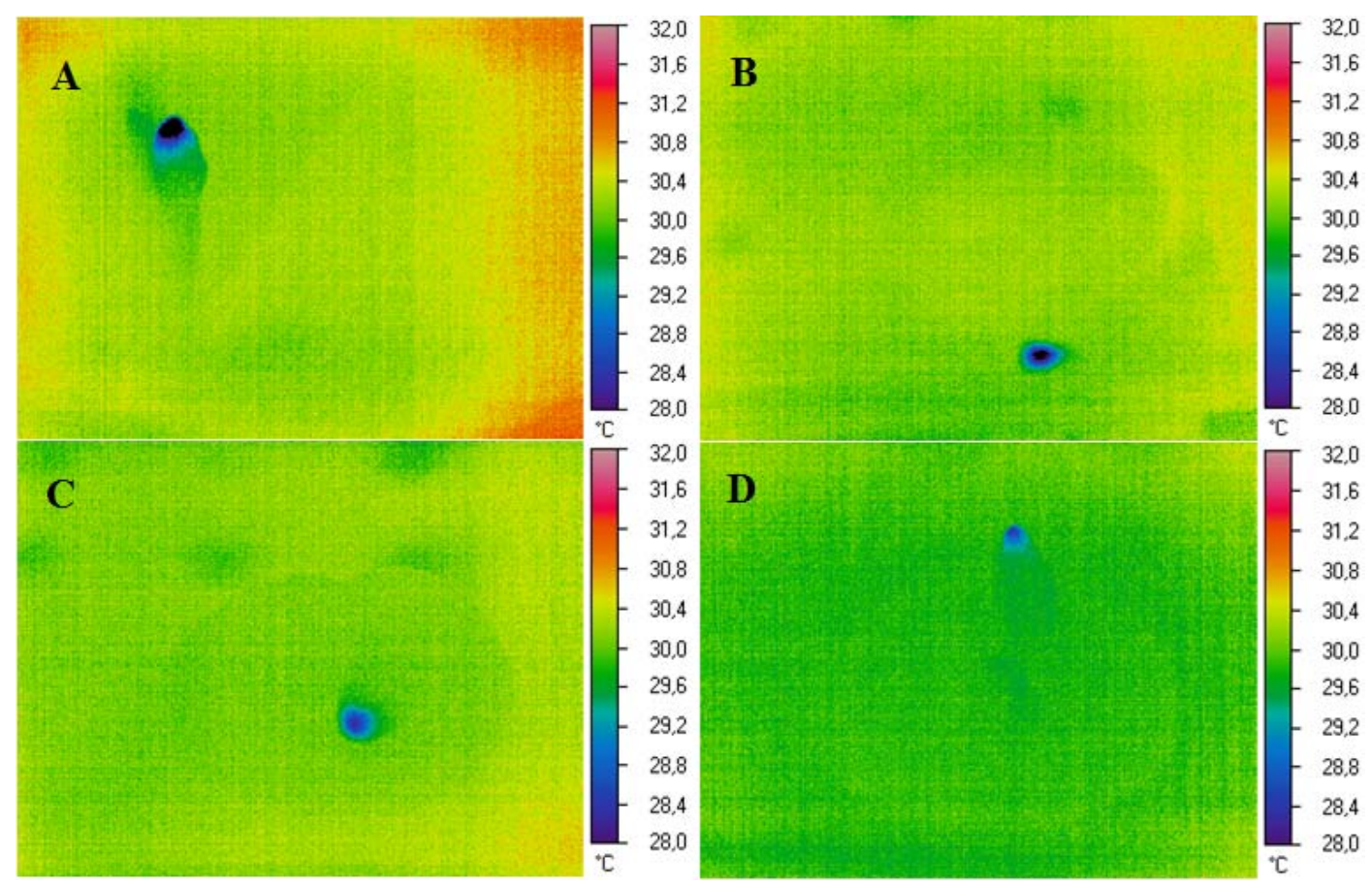

\section{5) Discussão:}

5.5.1) Metodologia: Com o avanço da tecnologia, a quantificação da temperatura corporal em serpentes tem se tornado progressivamente mais fácil e menos invasiva, possibilitando a tomada da temperatura dos animais sem a necessidade de manipulá-los, evitando o viés de uma eventual troca térmica e do estresse. Dentre as técnicas que não necessitam de contenção do animal, existem ao menos três recentemente definidas (Tein-Shun \& MingShung, 2005). Todas elas apresentam vantagens e desvantagens. O uso de termômetros intra-cloacais fixados, apesar de vastamente empregado, parece causar um grande desconforto em alguns animais e podem causar mudanças comportamentais e fisiológicas ocasionando respostas térmicas diferentes. O emprego de data loggers, apesar de ter 
aumentado consideravelmente nos últimos anos, ainda tem um custo elevado e uso limitado em animais de pequeno porte. A técnica de quantificação térmica através da imagem infravermelho, usada neste trabalho, mostrou-se bastante eficiente e acurada representando uma alternativa viável, essencialmente pela sua praticidade e baixo custo. No entanto, esta técnica indica a temperatura da superfície corpórea do animal. Porém, no presente estudo, a elevada correlação obtida entre a temperatura cloacal e a da pele, no experimento prévio, indicou a praticidade e confiabilidade do método, permitindo dados que são comparáveis aos citados na literatura. A tomada da temperatura cloacal em serpentes alimentadas implicaria em excessivo manuseio e perturbação, que poderiam provocar a regurgitação. A probabilidade de regurgitação aumentaria com as freqüentes tomadas de temperatura, como foi o presente protocolo experimental, em especial naquele grupo que ingeriu presas de maior tamanho.

5.5.2) Termogênese e "Specific Dynamic Action" - (SDA): A SDA foi descrita para um grande número de animais dos mais diversos grupos, porém sua ordem de grandeza nas serpentes tem atraído a atenção dos pesquisadores. (Andrade et al, 1997; Garrow \& Hawes, 1972; Machida, 1981; Costa \& Kooyman, 1984; Kalarani \& Davies, 1994; Secor, 1997; Secor \& Diamond 1997a; Secor et al, 2007). Os enormes valores de SDA citados na literatura e sua intrincada relação com a quantidade de alimento ingerida (e.g. Andrade et al, 1997; Secor \& Diamond, 1997b), suportam os dados apresentados neste trabalho. O estudo da termogênese pós-prandial em cascavel (Tattersall et al, 2004), apresenta muitas similaridades com os dados do presente trabalho, sendo que em ambos os picos térmicos 
ocorreram por volta das 30 horas pós-alimentação. Também houve uma relação positiva entre a resposta termofílica e a quantidade de alimento ingerido. No trabalho com a cascavel o $\Delta \mathrm{t}$ pós-prandial variou na ordem de 0.93 e $1.3^{\circ} \mathrm{C}$, para os grupos que receberam a menor e a maior porcentagem de alimento, respectivamente, aproximando-se muito dos valores obtidos no presente estudo. Este fato é importante, pois apesar da utilização de espécies diferentes ambos os trabalhos foram executados a uma mesma temperatura $\left(30^{\circ} \mathrm{C}\right)$ o que pode sugerir uma relação digestória termodependente. As diferenças na durabilidade das respostas termogênicas, no entanto, foram significantes e podem ser explicadas pelo maior tamanho dos animais utilizados no experimento com as cascavéis. Por possuírem uma maior massa e com isso uma maior capacidade de retenção térmica. Grandes respostas termogênicas já foram observadas em animais de maior massa corporal, com aumentos da ordem de $4^{\circ} \mathrm{C}$ em Pythons com data loggers implantados, o que pode estar relacionado ao maior SDA nestes animais. (Marcelini \& Peters, 1982).

\subsection{3) Implicações de elevados valores de SDA e respostas termogênicas: Apesar do} aumento da abordagem fisiológica do SDA em serpentes, um ponto fundamental, que tem sido pouco explorado, é a implicação da resposta termogênica. A digestão nos ectotérmicos, assim como outras performances fisiológicas, está intrinsecamente ligada à temperatura corporal, sendo que muitos animais munem-se de estratégias termorregulatórias comportamentais após a alimentação. As serpentes noturnas geralmente apresentam limitadas oportunidades de termorregular durante o período de atividade (Hertz et al, 1993). A impossibilidade ou mesmo a ausência de um comportamento termofílico pós-prandial é uma questão extremamente importante quando tratamos da ecologia de 
serpentes ( Regal, 1966; Lysenko \& Gillis, 1980; Shine \& Slip, 1988; Webb \& Whiting, 2005).

Como mencionado anteriormente (Hertz et al, 1993) nem todas as espécies de ectotérmicos vivem em ambientes que favorecem todas as suas performances fisiológicas máximas, como é o caso, da velocidade para certos geckonideos (Huey et al, 1989), e nem por isso estes animais tem seu desempenho reduzido (Angilletta et al, 2002). Partindo do pressuposto que a digestão é um processo que afeta bastante o desempenho do animal, já que está diretamente relacionada ao crescimento e desenvolvimento, uma importante questão que fica em aberto é: estes animais não viveriam em ambientes onde o desempenho digestório já é suficiente, sem a necessidade de respostas termofílicas? (Hertz, 1974; Mori et al, 2002) ou, o custo associado a esta tentativa de resposta termofílica seria demasiadamente alto? (Webb \& Whiting, 2005).

O custo locomotor, tanto energético quanto ligado ao risco de predação, pode ser especialmente elevado em determinados habitats (Huey \& Slatkin, 1976; Downes \& Shine, 1998) e se o associarmos a um grande aumento na massa a ser deslocada (no caso de uma grande ingesta), provavelmente este custo deve aumentar assombrosamente (Beck, 1996). Considerando estes aspectos, pontuamos que se determinados animais efetivamente não possuem um comportamento termofílico pós-prandial, a explicação seria, ou a ausência da necessidade, ou seja, o desempenho digestório naquela determinada temperatura não minimiza a aptidão da espécie, ou o custo para maximizar a digestão é por demais dispendioso sendo preferível que o animal permaneça numa temperatura de digestão subótima que o ônus da tentativa de reposta termofílica. 
Neste ponto o SDA e a termogênese dela resultante, por estarem intimamente ligadas ao baixo consumo energético das serpentes (Pough, 1983; Chappell \& Ellis, 1987) e à capacidade de ingerir grandes presas (Greene, 1997), podem ser o ponto crítico na compreensão da dinâmica digestória destes animais. É quase que intuitivo pensarmos que as serpentes, principalmente no caso das serpentes noturnas e de baixa atividade (sit and wait ambushers), que são grandes economizadoras de energia, utilizem, assim como todos os endotérmicos o principal subproduto do metabolismo aeróbico, o calor. Por isso é plausível que estes animais, principalmente após ingerir grandes proporções de presas, utilizem o calor gerado através de sua grande SDA para acelerar seu processo digestório diminuindo assim o alto custo associado a uma manobra termofílica pós-prandial. A utilização do calor metabólico nesses animais pode ser uma solução adaptativa ao desafio de maximizar um grande processo digestório frente a uma custosa possibilidade termorregulatória. 
Bibliografia:

Andrade, D. V.; Cruz-Neto, A. P.; Abe, A. S. (1997). Meal size and specific dynamic action in the rattlesnake Crotalus durissus durissus (Serpentes: Viperidae). Herpetologica $53,485-493$.

Angilletta, M. J. Jr.; Niewiarowski, P. H.; Navas, C. A. (2002). The evolution of thermal physiology in ectotherms. J. Thermal Biol. 27, 249-268.

Beck, D. D. (1996). Effects of feeding on body temperatures of rattlesnakes: a field experiment. Physiol. Zool. 69, 1442-1455

Bustard, H. R. (1967). Activity cycle and thermorregulation in Australian gecko Gehrya variegata. Copeia 1967, 753-758.

Campbell, J. A. \& Lamar, W. W. (2004). In Venomous of the western hemisphere, vol 1, Cornell Univers, Press, Ithaca, New York

Chappell, M. A. \& Ellis, T. M. (1987). Resting metabolic rates in boid snakes: allometric relationships and temperature effects. J. Comp. Physiol. B 157:227-235.

Costa, D. P. \& Kooyman, G. L. (1984). Contribution of specific dynamic action to heat balance and thermoregulation in the sea otter, Enhydra lutris. Physiol. Zool. 57, 199-203

Daltry, J. C.; Ross, T.; Thorpe, R. S.; Wuster, W. (1998). Evidence that humidity influences snake activity patterns: a field study of Malayan pit viper Calloselasma rhodostoma. Ecography, vol 21, pp 25-34.

Downes, S.; Shine, R. (1998). Heat, safety or solitude. Using habitat selection experiments to identify a lizard's priorities. Anim. Behav. 1387-1396. 
Fontanillas, P.; Depraz, A.; Giorgi, M. S.; Perrin, N. (2005). Nonshivering thermogenesis capacity associated to mitochondrial DNA haplotypes and gender in the greaterwhite-toothed shrew,Crocidura russula in Molecular Ecology 14, 661-670.

Garrow, J. S. \& Hawes, S.F. (1972). The role of amino acid oxidation in causing "specific dynamic action" in man. Br. F. Nutri. 27, 211

Grayson, K. L.; Cook, L. W.; Todd, J. M.; Pierce, D.; Hopkins, W. A.; Gatten, R. E. Jr.; Dorcas, M. E.(2005). Effects of prey type on specific dynamic action, growth, and mass conversion efficiencies in the horned frog, Ceratophrys cranwelli. Comparative Biochemistry and Physiology, Part A 141298 - 304

Greene, H. W. (1997). Snakes: The Evolution of Mystery in Nature. Berkeley: University of California Press.

Greenwald, O. E. \& Kanter M. E. (1979). The effects of temperature and thermorregulation on digestive efficiency in corn snakes: Elaphe guttata guttata. Physiol. Zool. 52, 398-408

Guyton, A. C. \& Hall, J. E. (2000) Textbook of Medical Physiology, 9 edth., W. B. Saunders company, chapters 72-73.

Harlow, P. S. \& Grigg, G. (1984). Shivering thermogenesis in a brooding diamond python, Python spilotes spilotes. Copeia 1984, 959-965.

Hertz, P. E (1974). Thermal passivity of a tropical forest lizard, Anolis polylepis. J. Herpetol., 8: 323-327.

Hertz, P. E.; Huey, R. B.; Stevenson, R. D.(1993). Evaluating Temperature Regulation by Field-Active Ectotherms: The Fallacy of the Inappropriate Question The American Naturalist, Vol. 142, No. 5. (Nov., 1993), pp. 796-818 
Huey, R. B.; Slatkin M. (1976). Cost and Benefits of Lizard Thermoregulation. The Quarterly Review of Biology, Vol. 51, No. 3 pp. 363-384.

Huey, R. B. (1982). Temperature physiology and ecology of reptiles. In Biology of Reptilia. (Edited by Gans C. and Pough F. H.), vol 12, pp 25-91. Academic press, London.

Huey, R. B. \& Hertz, P. E. (1984). Is a jack-of-all-temperatures a master of none? Evolution 38, 441-444.

Huey, R. B.; Niewiarowski, P. H.; Kaufmann, J.; Herron, J.C. (1989). Thermal biology of nocturnal ectotherms: is sprint performance of geckos maximal at low body temperatures? Physiol. Zool. 62, 488-504.

Hutchinson, V. H.; Dowling, H. G.; Vinegar, A. (1966). Thermoregulation in a brooding female Indian python, Python molurus bivittatus. Science 151, 694-696.

Jastroch, M.; Buckingham, J. A.; Helwig, M.; Klingenspor, M.; Brand, M. D. (2007). Functional characterisation of UCP1 in the common carp: uncoupling activity in liver mitochondria and cold-induced expression in the brain. J. Comp. Physiol. B 177:743-752

Kalarani, V. \& Davies, R. W. (1994). The bioenergetic costs of specific dynamic action and ammonia excretion in a freshwater predatory leech Nephelopsis obscura. Comp Biochem Physiol A 108:523-531.

Lang, J. W. (1979) Thermophilic response of the American alligator and American crocodile to feeding. Copeia 1979, 48-59.

Lignot, J. H.; Helmstetter, C.; Secor, S. M. (2005). Postprandial morphological response of the intestinal epithelium of the Burmese python (Python molurus). Comp. Biochem. Physiol. 141A, 280-291. 
Lillywhite, H. B. (1987) Temperature, energetics, and physiological ecology. In snakes: Ecology and Evolutionary Biology. (Edited by Seigel R. A.; Collins J. T. And Novak S. S.), pp 422-477. Macmillan, New York.

Lysenko, S. \& Gillis, J. E. (1980). The effect of ingestive status on the thermoregulatory behavior of Thamnophis sirtalis sirtalis and Thamnophis sirtalis parietalis. J. Herpetol. 14, $155-159$

Machida, Y. (1981). Study of specific dynamic action on some freshwater fishes. Rep Usa Mar Biol Inst Kochi Univ 3:1-50

Marcellini, D. L. \& Peters, A. (1982). Preliminary observations on endogenous heat production after feeding in Python molurus. J. Herpetol. 16, 92-95

McCue, M. D.; Bennett, A. F.; Hicks, J. W. (2005). The Effect of Meal Composition on Specific Biology, Universityof California, Irvine

Mcginnis, S. M. \& Moore, R. G. (1969). Thermorregulation in Boa constrictor (Boa constrictor). Herpetologica 25, 38-45.

Mori, A.; Toda, M.; Ota, H. (2002). Winter activity of $O \_o p h i s$ okina_ensis in the humid subtropics: foraging on breeding frogs under cool temperature. - In: Hoggren, M. (ed.), Biology of the vipers. Uppsal Peterson, C. R

Mzilikazi, N. \& Lovegrove, B. G. (2006). Noradrenalin induces thermogenesis in a phylogenetically ancienteutherian mammal, the rock elephant shrew, Elephantulus myurus in J. Comp. Physiol. B 176: 75-84.

Naulleau, G. (1983). The effects of temperature on digestion in Vipera aspis. J. Herpetol. $16,166-177$. 
Ott , B. D. \& Secor, S.M. (2006). Adaptive regulation of digestive performance in the genus Python. The Journal of Experimental Biology 210, 340-356

Overgaard, J. \& Wang, T. (2002). Increase blood oxygen affinity during digestion in the snake Python molurus. J. Exp. Biol., vol 205, pp 3327-3334.

Peterson, C. R.; Gibson, A. R.; Dorcas, M. E. (1993). Snake thermal ecology: the causes and consequences of body temperature variation. In: Seigel,R.A., Collins,J.T. (Eds.),Snakes: Ecology and Behavior. McGraw-Hill,Inc., New York,pp. 241-314.

Pough, F. H. (1983) Amphibians and reptiles as low-energy systems, In Behaviorral Energetics: The Cost of survival in Vertebrades (W, P, Aspley and S,I Lustyc), pp 141-188, Ohio State Univers, Press, Columbus

Regal, P. J. (1966) Thermophilic response following feedingin certain reptiles. Copeia 1966, 588-590.

Secor, S. M. \& Diamond J. (1997a). Determinants of post-feeding metabolic response in Burmese pythons (Python molurus).Physiol Zool 70:202-212.

Secor, S. M. \& Diamond, J. (1997b) Effects of meal size on postprandial responses in juvenile Burmese pythons (Python molurus).Am. J. Physiol. 272:R902-R912.

Secor, S. M. (2003). Gastric function and its contribution to the postprandial metabolic response of the Burmese python Python molurus. J. Exp. Biol.

206, 1621-1630.

Secor S. M (2005) Evolutionary and cellular mechanisms regulating intestinal performance of Amphibians and reptiles. Inter. Comp. Biol., vol 45, pp 282-294. 
Secor, S. M. \& Boehm, M. C. (2006). Specific dynamic action of ambystomatid salamanders and the effects of meal size, meal type, and body temperature. Physiol. Biochem. Zool. 79, 720-735.

Secor S. M.; Wooten J. A.; Cox C. L.(2007). Effects of meal size, meal type, and body temperature on the specific dynamic action of anurans. J. Comp. Physiol. B 177:165-182.

Shine, R. \& Lambeck, R. (1985). A radiothelemetric study of movements, thermorregulation and habitat utilization of Arafura filesnake (Serpentes: Acrochordidae), Herpetologica, 41: 351 .

Shine, R. \& Slip, D. J. (1988). Thermophilic response to feeding of diamond python, Morelia s. spilota (Serpentes: Boiidae) Comparative Biochemistry Physiology, vol 89a, n4, pp 645-650.

Shine, R., Madsen, T., Elphick, M., Harlow, P., (1996). The influence of nest temperatures and maternal thermogenesis on hatchling phenotypes of water pythons. Ecology 78, 1713-1721.

Starck, J. M. \& Beese, K. (2002). Structural flexibility of the small intestine and liver of garter snakes in response to feeding and fasting. J. Exp. Biol.,vol 205, pp 1377-1388.

Tattersall, G. J.; Milsom, W. K.; Abe, A. S.; Brito, S. P.; Andrade, D. V. (2004). The thermogenesis of digestion in rattlesnakes. The Journal of Experimental Biology 207, 579585.

Tsai, Tein-Shun.; \& Tu, Ming-Shung. (2005). Postprandial thermophily in Chinese green tree vipers, Trimeresurus stejnegeri stejnegeri: inferring factors on snake temperature selection in a thigmothermal gradient. Journal of thermal biology 30, 423-430. 
Toledo, L. F.; Abe, A. S. \& Andrade, D. V. (2003). Temperature and meal size effects on the postprandial metabolism and energetics in a Boid snake. Physiological and Biochemical Zoology, 76(2):240-246.

Tu, M. C.; Hutchison, V. H.(1995). Lack of postprandial thermophily in diamond back watersnakes, Nerodia rhombifera. Comp. Biochem. Physiol. 110A,21-25.

Van Mierop, L.H.S., Barnard, S.M., (1978). Further observations on thermoregulation in the brooding female Python molurus bivittatus (Serpentes: Boidae). Copeia 1978, 615-621.

Webb, J. K. \& Whiting, M. J. (2005). Why don't small snakes bask? Juvenile broadheaded snakes trade thermal benefits for safety. Oikos 110, 515-522.

Wang, T.; Zaar, M.; Arvedsen, S.; Vedel-Smith, C.; Overgaard, J.(2003). Effects of temperature on the metabolic response to feeding in Python molurus. Comp. Biochem. Physiol. 133A, 519-527. 


\section{Capítulo 6.0:}

\section{1) Discussão final:}

A compilação dos resultados citados nos capítulos anteriores aponta para uma intrincada relação entre os hábitos e a termobiologia de Bothrops moojeni. A falta de movimentação dos animais durante o dia, agregada a busca por temperaturas significantemente mais baixas está de acordo com a hipótese de que quando não estão ativos, os animais procuram baixar ao máximo seu consumo energético, embora nem todas as serpentes contemplem essa mesma regra (Pough, 1983; Tu \& Tsai, 2005). O horário de atividade dos animais poderia, em teoria, refletir sua necessidade termorregulatória, já que nas primeiras horas da noite existe maior disponibilidade de locais apropriados para o aquecimento na natureza. Entretanto, o pico de atividade também foi observado nos animais da arena térmica, o que invalida essa hipótese e abre um leque de novas explicações para o perfil de atividade destes animais. Os dados referentes à termorregulação obtidos no laboratório podem ser pouco fiéis ao que de fato ocorre na natureza, já que em vida livre existe um custo e um hall limitado de possibilidades termorregulatórias. Infelizmente dados sobre a termorregulação da espécie em vida livre são inexistentes, entretanto, é provável que rotineiramente, a termorregulação não exerça uma importância tão grande na vida destes animais. Por ser um animal noturno e pouco ativo, é provável que Bothrops moojeni possa manter seu baixo nível de atividade mesmo sob regimes térmicos pouco favoráveis, sem prejudicar seu fitness por conta disso. A dificuldade na manutenção de um nível ótimo de atividade sob condições fora das ideais, pode muitas vezes, conduzir os animais a eventos de hibernação ou estivação, que apesar de serem comuns aos crotalinae habitantes de áreas aonde o inverno é mais rígido, nunca foram relatados para a espécie em questão 
(Gregory,1982; Nogueira et al, 2003; Campbell \& Lamar, 2004). Entretanto, devido a grande termodependência do processo digestório, a manutenção térmica pode ser crucial (Lillywhite, 1987; Mori et al, 2002). A maior detecção da termofilia pós-prandial durante o dia, quando as temperaturas procuradas pelos animais jejunos foram mais baixas, aliada ao fato de que houve regurgitação em um dos animais que não apresentou a resposta termofílica diurna, endossam a necessidade da manutenção de temperaturas adequadas para um processo digestório maximizado.

O fato de a resposta termofílica ser inversamente proporcional a quantidade de alimento, pode, a princípio, causar certa confusão, já que refeições maiores necessitam de mais energia para serem digeridas (Andrade, 1997; Toledo et al, 2003 ) e o metabolismo aeróbico também apresenta um alto grau de termodependência (Bennett, 1982). No entanto, uma maior resposta termogênica poderia, em tese, tamponar o comportamento termofílico. Embora a combinação dos dados obtidos através dos experimentos da termofilia e termogênese sugira a ocorrência deste tamponamento, é a igualdade das temperaturas corporais pós-prandiais entre todos os grupos alimentares que parece sustentar esta hipótese.

O estudo das temperaturas preferenciais, respostas termofílicas, mecanismos termogênicos, temperaturas de ótima atividade, mensurações metabólicas e relações hídricas, são fundamentais para a compreensão do comportamento das serpentes na interface entre as necessidades fisiológicas e as imposições ecológicas.

Neste tema, as serpentes noturnas e de baixa atividade figuram como incríveis modelos de estudo, que se contrapõem aos modelos mais clássicos de ectotérmicos diurnos e de alta atividade (Huey; 1982). Pesquisas futuras que incorporem estes modelos e que detalhem a 
influência da temperatura nas diversas atividades destes animais servirão como pedra fundamental no conhecimento da evolução da ecofisiologia dos ectotérmicos.

\section{2) Conclusões Finais:}

Com os dados coletados ao longo do trabalho pudemos concluir que:

- A técnica de monitoramento por vídeo aliada ao monitoramento térmico da arena é uma técnica factível para mensurações de Tset e resposta termofílica.

- Bothrops moojeni apresentou um intervalo de temperatura preferencial próximo as temperaturas buscadas por outras serpentes crotalinae, não diferindo significativamente entre machos e fêmeas.

- Bothrops moojeni apresentou diferenças em suas temperaturas preferenciais durante os períodos de atividade e inatividade.

- Bothrops moojeni pode apresentar resposta termofílica pós-prandial, sendo esta dependente do período e da quantidade de alimento ingerido.

- A termofilia pós-prandial não apresentou diferenças quanto ao sexo dos animais.

- A presença de anteparos em uma das arenas não afetou a resposta termofílica dos animais.

- É possível ser estabelecida uma correlação entre a temperatura da pele e a temperatura cloacal dos animais, permitindo o uso de tomadas térmicas sem a contenção dos animais.

- Bothrops moojeni é uma espécie que se desloca essencialmente durante a noite, principalmente no primeiro terço desta.

- A quantidade e o horário de atividade dos animais não variaram significativamente entre os dois sexos. 
- A inversão de fotoperíodo não mudou o padrão de atividade, sendo que os animais continuaram a deslocar-se preponderantemente no mesmo período (primeiro terço do período noturno).

- A quantidade de alimento ingerido influenciou no deslocamento dos animais, sendo que os animais que comeram as maiores proporções alimentares (20\% e 40\%) diminuíram suas taxas de deslocamento.

- Bothrops moojeni apresenta termogênese pós-prandial, sendo que a amplitude e duração desta estão positivamente relacionadas à quantidade de alimento ingerida.

- As temperaturas mais baixas procuradas durante o dia e a inatividade durante o período, parecem estar relacionadas à economia energética.

- A maior detecção da termofilia pós-prandial durante o dia parece estar relacionada às temperaturas mais baixas procuradas por estes animais durante o repouso, visto que podem ser demasiadamente baixas para a manutenção de um processo digestório maximizado.

- A diminuição de atividade dos animais que comeram as maiores porcentagens de alimento parece estar relacionada à desnecessidade de uma resposta termofílica comportamental, visto que o componente termogênico nestes animais é maior.

- A igualdade das temperaturas corporais pós-prandiais entre todos os grupos alimentares parece estar fortemente associada a componentes comportamentais (termofilia pósprandial) e fisiológicos (termogênese pós-prandial). Assim os grupos que apresentaram uma pronunciada termogênese não necessitaram de uma ampla resposta termofílica para manter suas temperaturas corporais similares aos animais que apresentaram alta resposta termofílica, porém um menor grau termogênico. 
Bibliografia:

Andrade, D. V.; Cruz-Neto, A. P.; Abe, A. S. (1997). Meal size and specific dynamic action in the rattlesnake Crotalus durissus durissus (Serpentes: Viperidae). Herpetologica $53,485-493$.

Bennet, A. F. (1982) The energetics of reptilian activity. In Biology of Reptilia. (Edited by Gans C. and Pough F. H.), vol 13, pp 155-194. Academic press, London.

Campbell, J. A. \& Lamar, W. W. (2004). In Venomous of the western hemisphere, vol 1, Cornell Univers, Press, Ithaca, New York.

Gregory, P. T. (1982). Reptilian hibernation. In Biology of Reptilia. (Edited by Gans C. and Pough F. H.), vol 13, pp 53-140. Academic press, London.

Huey, R. B. (1982). Temperature physiology and ecology of reptiles. In Biology of Reptilia. (Edited by Gans C. and Pough F. H.), vol 12, pp 25-91. Academic press, London. Lillywhite, H. B. (1987) Temperature, energetics, and physiological ecology. In snakes: Ecology and Evolutionary Biology. (Edited by Seigel R. A.; Collins J. T. And Novak S. S.), pp 422-477. Macmillan, New York.

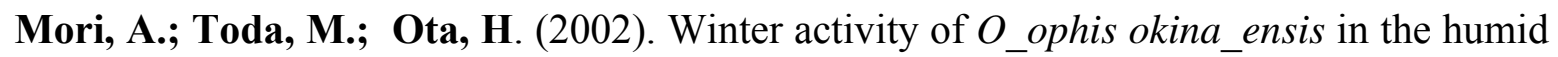
subtropics: foraging on breeding frogs under cool temperature. - In: Hoggren, M. (ed.), Biology of the vipers. Uppsal Peterson, C. R

Nogueira, C.; Sawaya, R. J.; Martins M. (2003). Ecology of the pitviper, Bothrops moojeni, in the Brazilian cerrado. J. Herpetol., vol 37, n4, pp 653-659. 
Pough, F. H. (1983) Amphibians and reptiles as low-energy systems, In Behaviorral Energetics: The Cost of survival in Vertebrades (W, P, Aspley and S,I Lustyc), pp 141-188, Ohio State Univers, Press, Columbus

Tattersall, G. J.; Milsom, W. K.; Abe, A. S.; Brito, S. P.; Andrade, D. V. (2004). The thermogenesis of digestion in rattlesnakes. The Journal of Experimental Biology 207, 579585.

Toledo, L. F.; Abe, A. S. \& Andrade, D. V. (2003). Temperature and meal size effects on the postprandial metabolism and energetics in a Boid snake. Physiological and Biochemical Zoology, 76(2):240-246.

Tsai, Tein-Shun.; \& Tu, Ming-Shung. (2005). Postprandial thermophily in Chinese green tree vipers, Trimeresurus stejnegeri stejnegeri: inferring factors on snake temperature selection in a thigmothermal gradient. Journal of thermal biology 30, 423-430. 